Failure Modes and Diagnostic Signatures Working Group - Ignition Diagnostics Requirements Update

C. Cerjan, S. Haan, S. Hatchett, J. Koch

April 6, 2007 
This document was prepared as an account of work sponsored by an agency of the United States Government. Neither the United States Government nor the University of California nor any of their employees, makes any warranty, express or implied, or assumes any legal liability or responsibility for the accuracy, completeness, or usefulness of any information, apparatus, product, or process disclosed, or represents that its use would not infringe privately owned rights. Reference herein to any specific commercial product, process, or service by trade name, trademark, manufacturer, or otherwise, does not necessarily constitute or imply its endorsement, recommendation, or favoring by the United States Government or the University of California. The views and opinions of authors expressed herein do not necessarily state or reflect those of the United States Government or the University of California, and shall not be used for advertising or product endorsement purposes.

This work was performed under the auspices of the U.S. Department of Energy by University of California, Lawrence Livermore National Laboratory under Contract W-7405-Eng-48. 


\title{
Failure Modes and Diagnostic Signatures Working Group \\ Ignition Diagnostics Requirements Update \\ February 2007
}

\author{
C. Cerjan, S. Haan, S. Hatchett, J. Koch
}

\begin{abstract}
$\underline{\text { Summary }}$
We have performed an initial assessment of the sensitivity of various expected ignition diagnostic signatures to ignition failure modes using one and two-dimensional hydrodynamics simulations and post-processed simulated diagnostic output. As a result of this assessment, we recommend several changes to the current requirements for the ignition diagnostic suite. These recommendations are summarized in Table 1.
\end{abstract}




\section{1) Introduction}

The Failure Modes and Diagnostic Signatures Working Group has been exploring how we might recover from a failure to achieve ignition by analysis of simulated diagnostic data. In order to standardize the discussion of dissimilar failure modes, the following methodology is adopted. First, we choose a parameter that could plausibly be out of specification, and increase it beyond specification until the resulting simulated implosion yield is $1 \mathrm{MJ}$. We then multiply this parameter value by 1.5 , resulting in what is typically a "hard failure" with a yield in the $\sim 10-100 \mathrm{~kJ}$ range. For these simulated hard failures, we generate simulated diagnostic data for the current ignition diagnostic suite. These diagnostic data are:

1) Primary (12-17 MeV) neutron yield.

2) Downscattered (6-10 MeV) neutron yield, from polar and equatorial views.

3) Tertiary ( $>22 \mathrm{MeV}$ ) neutron yield, from polar and equatorial views.

4) Neutron bang time from fusion gamma rays.

5) Space and time-integrated ion temperature from neutron time-of-flight Doppler broadening.

6) Time-integrated primary neutron image, from polar and equatorial views.

7) Time-integrated downscattered neutron image, from polar and equatorial views.

8) Time-integrated emission x-ray image (> $20 \mathrm{keV}$ ), from polar and equatorial views.

We also generated simulated diagnostic data from other proposed new or modified diagnostics, including:

1) Neutron burn duration from fusion gamma rays.

2) X-ray (> $20 \mathrm{keV})$ bang time.

3) X-ray ( $>20 \mathrm{keV}$ ) burn duration.

4) Absolute emission $x$-ray yield ( $>20 \mathrm{keV})$.

5) ARC-backlit time-gated x-ray image.

We have explored a variety of failure modes in one and two dimensional simulations, with the initial goal of exploring how sensitive the various diagnostics are to failure mode, and using this sensitivity to assess the diagnostic performance requirements that are necessary in order to differentiate between failure modes.

This report summarizes the results of this initial investigation, and proposes new requirements that we believe will be important to improve our understanding of failed implosions and help us assess what to change in order to move closer to ignition on subsequent attempts. We defer an exploration of ARC backlit imaging to a later memo. 


\section{2) Usefulness of multiple lines of sight for neutron diagnostics}

Examination of the seven two dimensional simulations completed to date offers an initial assessment of the value of measuring angular variations in the scattered neutron signals. Predictions for both the downscattered primary $(6-10 \mathrm{MeV})$ and upscattered tertiary $(>22 \mathrm{MeV})$ neutron signals along the polar and equatorial axes were obtained from post-processing the existing two-dimensional simulation database, which currently focuses solely on asymmetric drive conditions and not on more realistic mixtures of failure mode contributions that would tend to suppress systematic angular variations. The effect of the alternating signs of the asymmetry will be reflected in enhanced or depleted fuel density distribution along the polar or equatorial axes, which, in turn, produces an asymmetric distribution of scattered neutrons.

Figure 1 shows the results for downscattered neutrons. The fraction of downscattered neutrons with respect to the total number of primary neutrons (12-17 $\mathrm{MeV}$ ) for either axis is plotted against the failure mode. The designation of the failure mode is $\mathrm{P}$ for positive; $\mathrm{N}$ for negative; the number indicates the Legendre mode. For example, P4N6 is a combination of a positive Legendre mode 4 and a negative Legendre mode 6 asymmetric drive conditions. As expected, the deviations in the drive conditions are reflected in the fractional variations. For example, equatorial scattering dominates polar scattering for the qualitatively similar N4 and P6 drive conditions, and polar scattering dominates equatorial scattering for P4 and N6. It should be noted that large fuel density variations might not be tracked by the polar or equatorial lines of sight. An example in this figure is the nearly identical fractional values for P4. In this case, of course, the material peak lies in between the two chosen axes with approximately the same material depletion along the two axes.

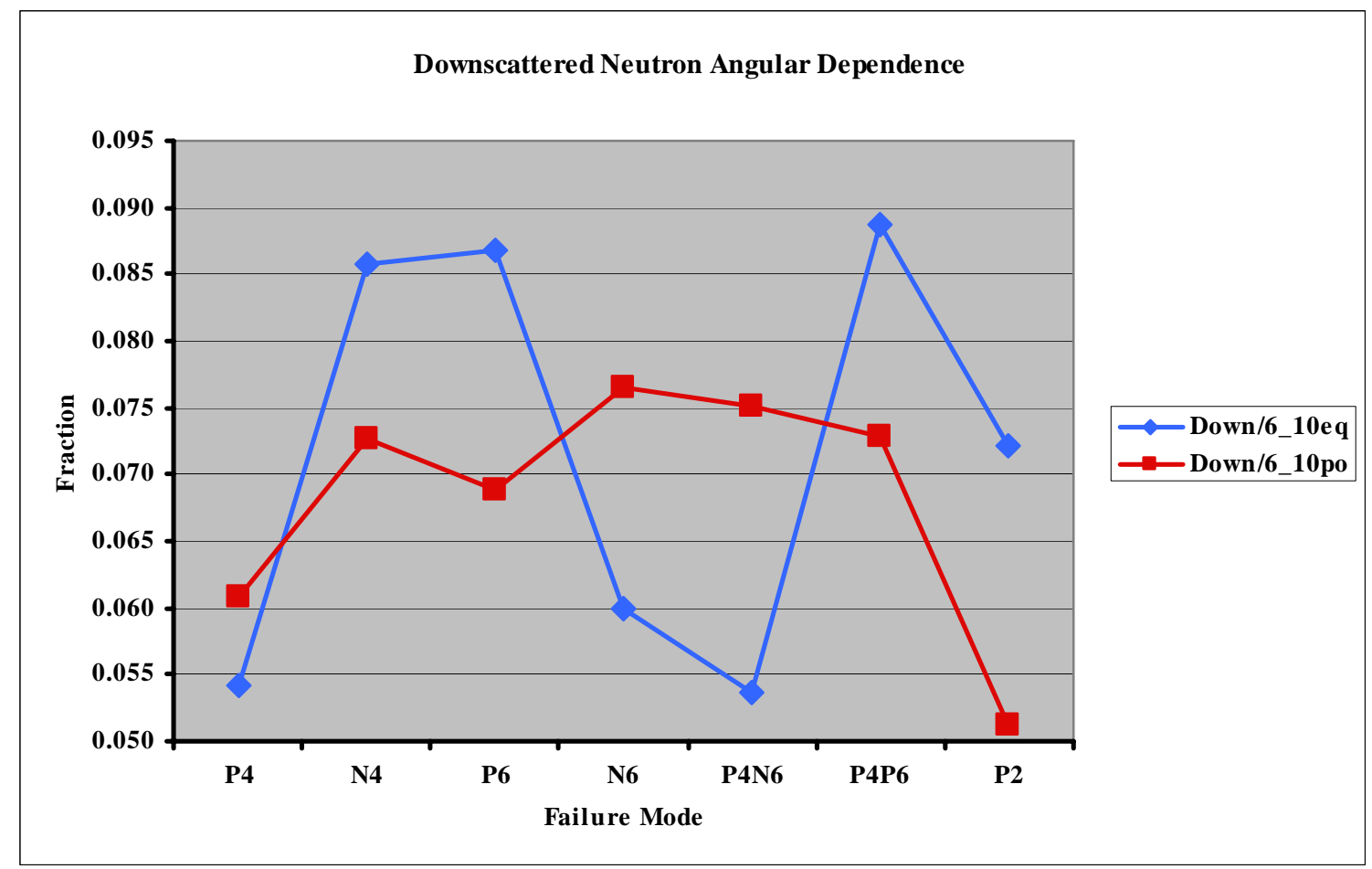

Figure 1. Downscattered neutron equatorial and polar scattering fraction plotted as a function of failure mode. The blue (red) line is the equatorial (polar) fraction. 
Clearly the overall angular deviations are not large. It will be difficult experimentally to observe this fractional variation since approximately $1 \%$ measurement precision will be required for each individual diagnostic (polar and equatorial). On the basis of these few simulations, there is no compelling reason for an additional downscattered neutron spectroscopy line of sight, especially since the neutron imaging diagnostics also track these same angular variations.

The same conclusions may be reached for the tertiary neutron scattering signal. Figure 2 is the analogous plot to Figure 1 for the case of the tertiary fraction. In this case, due to the significantly lowered signal, the experimental precision requirements are even more daunting, about $0.001 \%$, with little advantage obtained over similar neutron imaging diagnostic information. Even in ideal circumstances it is clear that the absolute angular variation is not as great as that expected for the downscattered fraction.

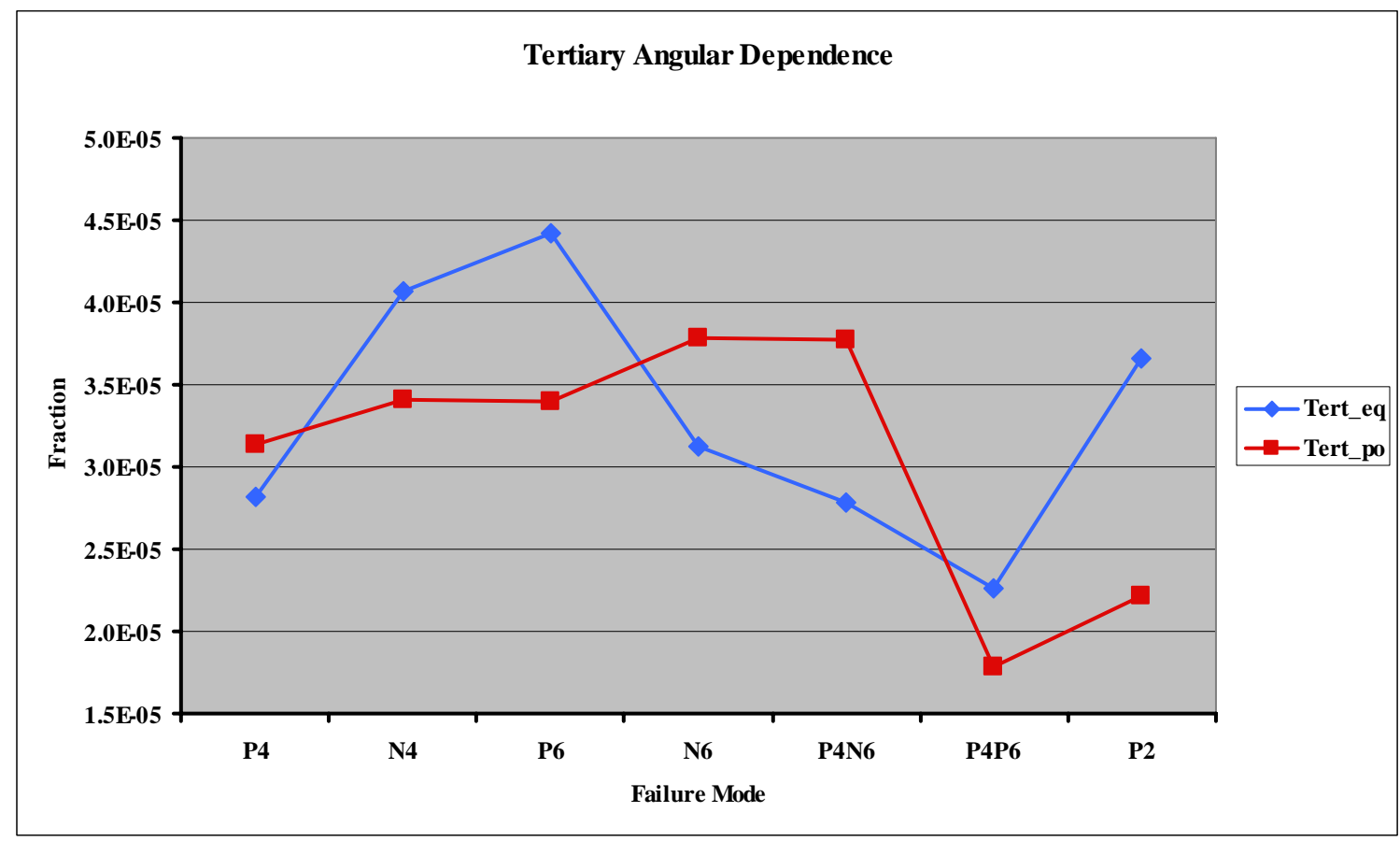

Figure 2. Tertiary neutron equatorial and polar scattering fraction plotted as a function of failure mode. The blue (red) line is the equatorial (polar) fraction

3) Utility of $\mathrm{T}_{\mathrm{i}}$, neutron fractions, bangtimes and burn durations, and x-ray image brightness

The existing one- and two-dimensional simulation database provides an assessment of the sensitivity of various neutron and x-ray diagnostic signatures to particular failure modes. It would be desirable ideally to find unique failure mode signatures under realizable experimental conditions, but in the very likely combination of 
mixed failure modes and experimental uncertainties it will be necessary to search for weaker correlations between the observations and failure modes.

In order to discover potential correlations, a representative number of strictly onedimensional and selective two-dimensional failure modes were simulated and analyzed. The one-dimensional simulations included variations in the opacity, oxygen content, drive timing errors, electron conduction, and charged particle deposition range. The twodimensional simulations were restricted to an examination of asymmetric drive conditions. The diagnostic quantities of interest were then derived from post-processing these calculations.

Ion temperature is an obvious diagnostic choice since ignition will depend critically upon achieving a suitably high temperature. The simulated ion temperature is plotted as a function of failure mode in Figure 3. As is obvious from the plot, ion temperature is not an especially sensitive failure diagnostic. Most of the two-dimensional failure modes, for example, have nearly indistinguishable ion temperatures, as do closely related one-dimensional failure modes such as low and high opacity failures.

Experimentally, $1 \mathrm{keV}$ precision would probably be sufficient to determine the range of the failure.

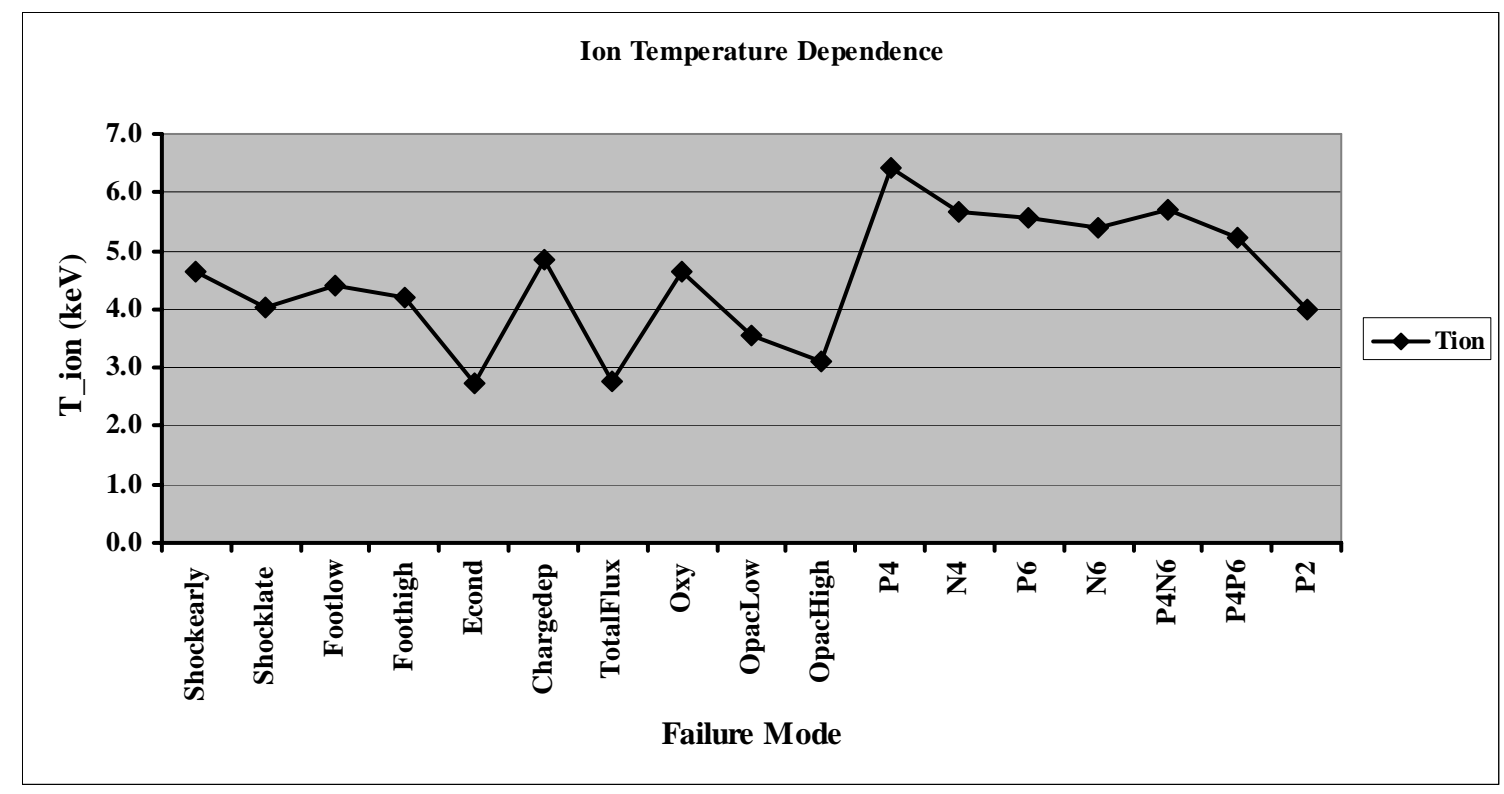

Figure 3. Ion temperature plotted as a function of failure mode.

Two potentially more sensitive failure diagnostics are the evaluations of the energetically downscattered and upscattered neutron fractions. These quantities are more challenging to determine experimentally, so the required accuracy limits must be determined. A plot of these scattered fractions as a function of failure mode is given in Figure 4. In order to display both quantities on a single plot, the scattered fraction is divided by the maximal scattered fraction value. For example, the largest tertiary scattered fraction was found for the charged particle deposition failure mode and all other tertiary scattered fractions were normalized to this value. The scattered fractions are seen to be more sensitive to failure mode, though there is no simple, unique correspondence. A downscattered neutron fraction measurement that is accurate to about $10 \%$ would 
probably be adequate to distinguish the variations, while the tertiary neutron fraction requires about a factor of two increase in accuracy to be generally useful. Although the secondary and tertiary fractions roughly track one another, there are a few significant differences that might discriminate among some failure modes. There are also outlying points that could be distinguished from the others with reduced measurement accuracy, perhaps $30 \%$ for downscattered neutrons and $50 \%$ for tertiary neutrons.

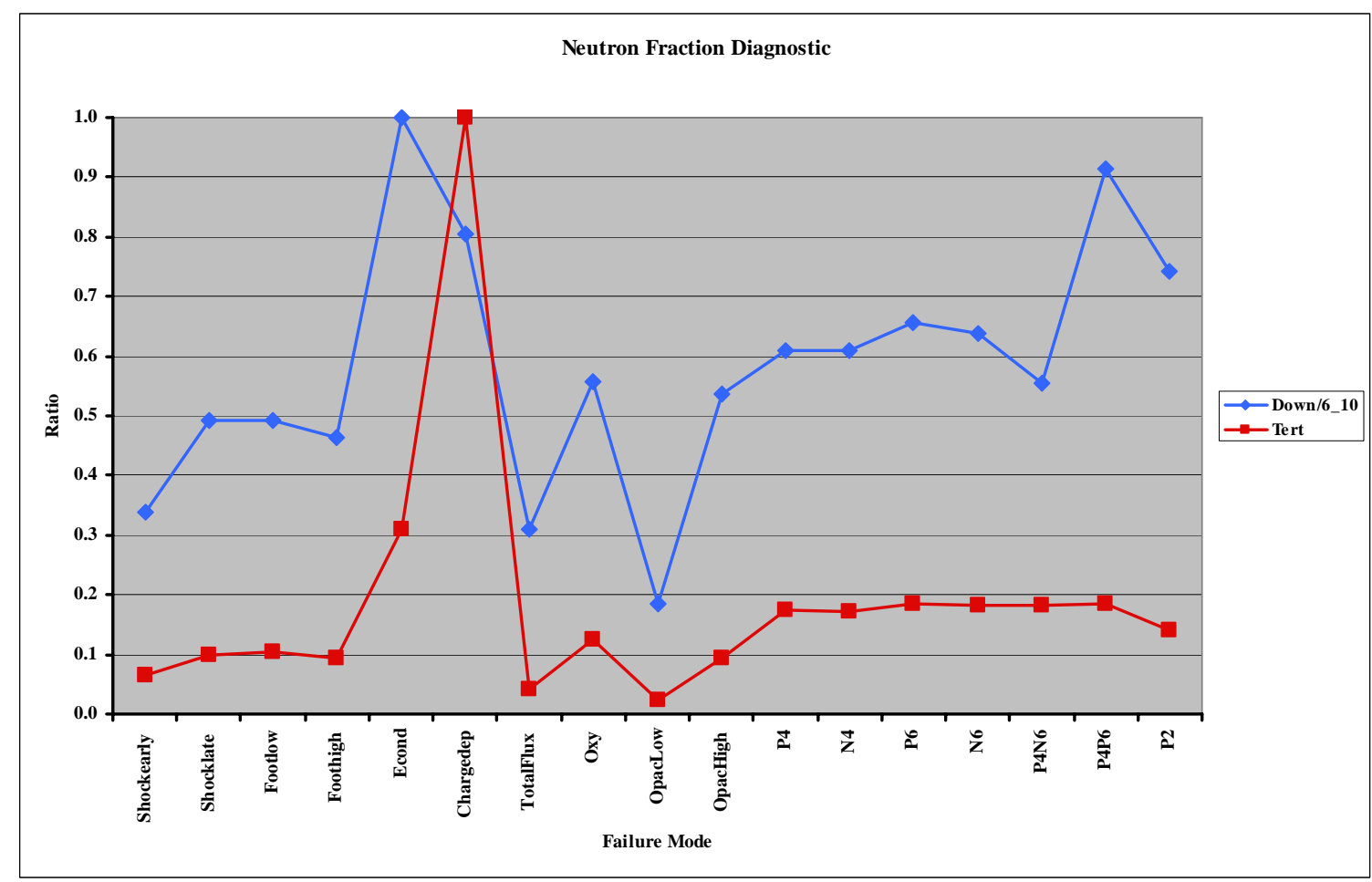

Figure 4. Downscattered (blue line) and tertiary (red line) neutron fractions scaled to maximal value.

Time-dependent diagnostics for both gamma ray and x-ray output will probably be limited to determinations of the bang times and burn widths. As demonstrated in Figure 5, neither bang time is a particularly sensitive diagnostic, but there are certainly clear signatures for some failure modes such as drive timing or opacity failures. It is also interesting to note that the gamma and x-ray bang times are essentially redundant. In this plot, the offset is defined as the difference in bang time from a nominal, optimal value. A time resolution of about 50 ps appears to be sufficient to provide useful information. 


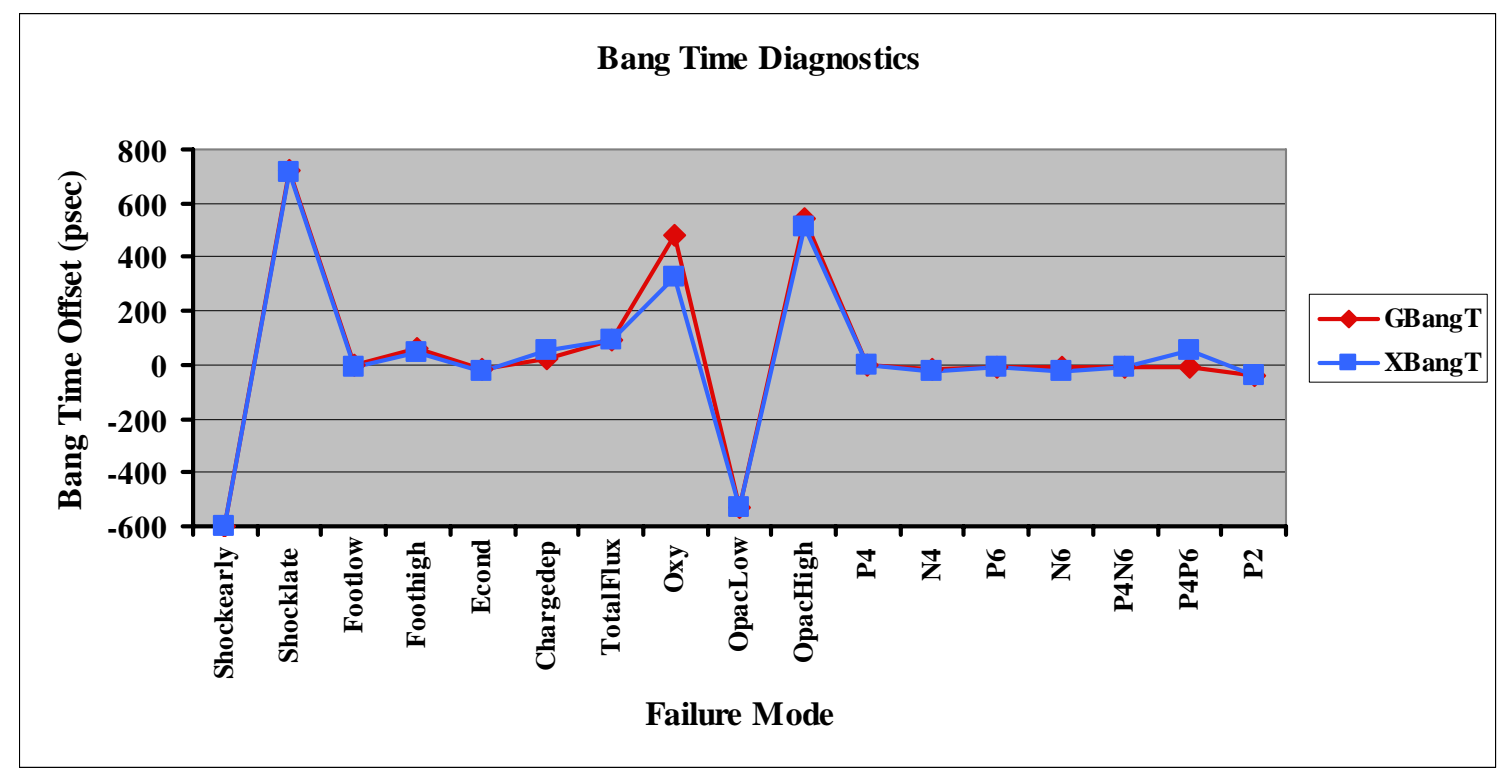

Figure 5. X-ray (blue line) and gamma ray (red line) bang time offsets plotted as a function of failure mode.

Another related quantity is the burn width associated with either gamma ray or $\mathrm{x}$ ray emission. As the data contained in Figure 6 demonstrate, there is significant variability in the burn widths as a function of failure mode. Furthermore, in contrast to the bang time measurements, substantial differences between the x-ray and gamma ray burn widths exist, suggesting that both diagnostic signatures would be valuable. The close lying values would require $10 \mathrm{ps}$ time resolution to distinguish them. On the other hand, there are large (> $50 \mathrm{ps)} \mathrm{differences} \mathrm{for} \mathrm{some} \mathrm{failure} \mathrm{modes} \mathrm{even} \mathrm{among} \mathrm{the}$ otherwise more subtle two-dimensional cases. Burn width information appears to be both qualitatively and quantitatively useful. 


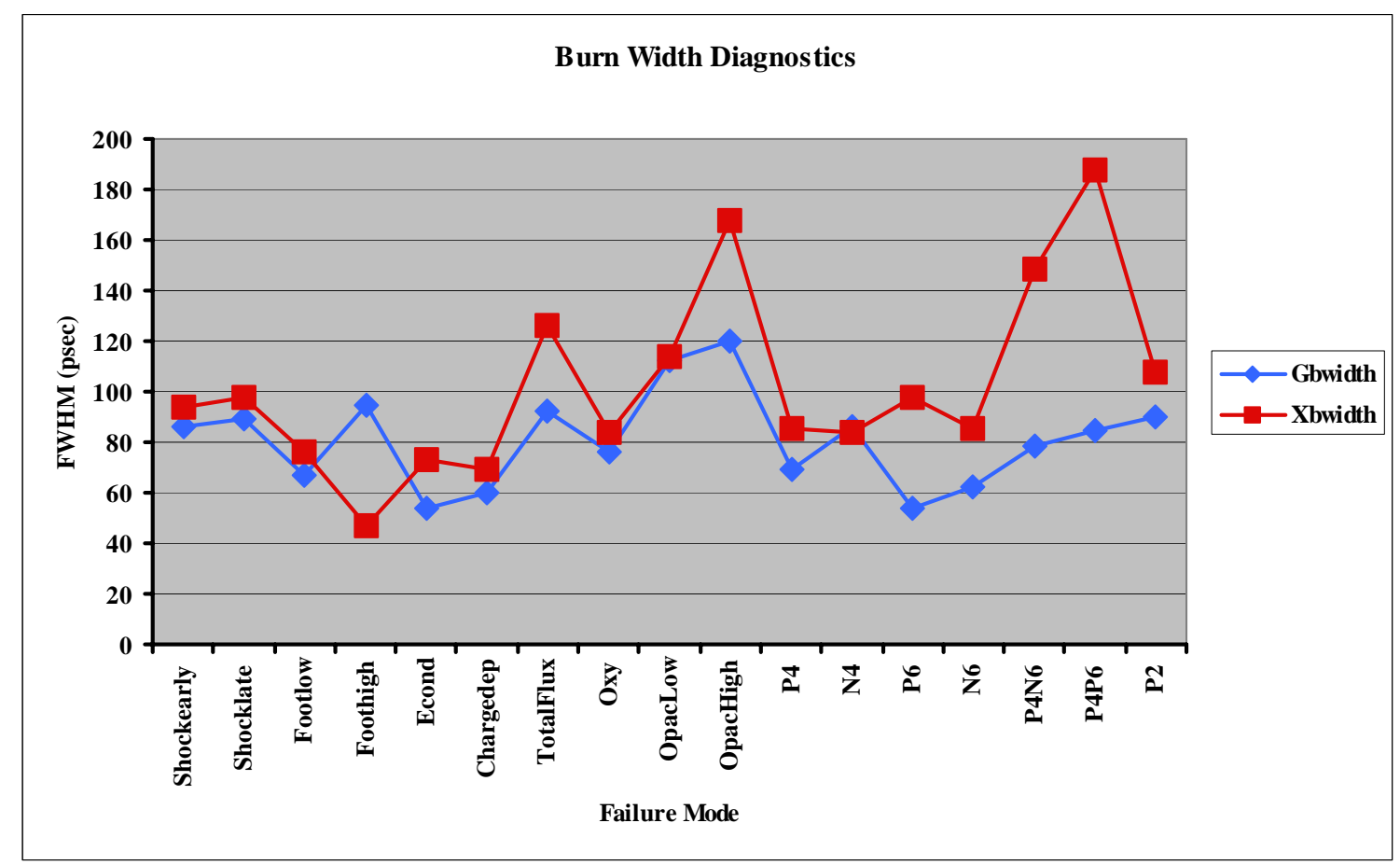

Figure 6. X-ray (red line) and gamma ray (blue line) burn widths plotted as a function of failure mode.

Another valuable x-ray diagnostic signature would be the image brightness. The expected variation in this quantity as a function of failure mode is depicted in Figure 7, where differences of a factor of 10 or more distinguish among some of the onedimensional failure modes. Although an absolutely calibrated, high precision measurement might be difficult, it appears that even a coarse (factor of 2) measurement could separate most of the one-dimensional failure modes from the asymmetric drive failures since the latter are uniformly large. As another example, this diagnostic signature alone nearly identifies one particular failure mode -- unexpectedly large ablator shell opacity. 


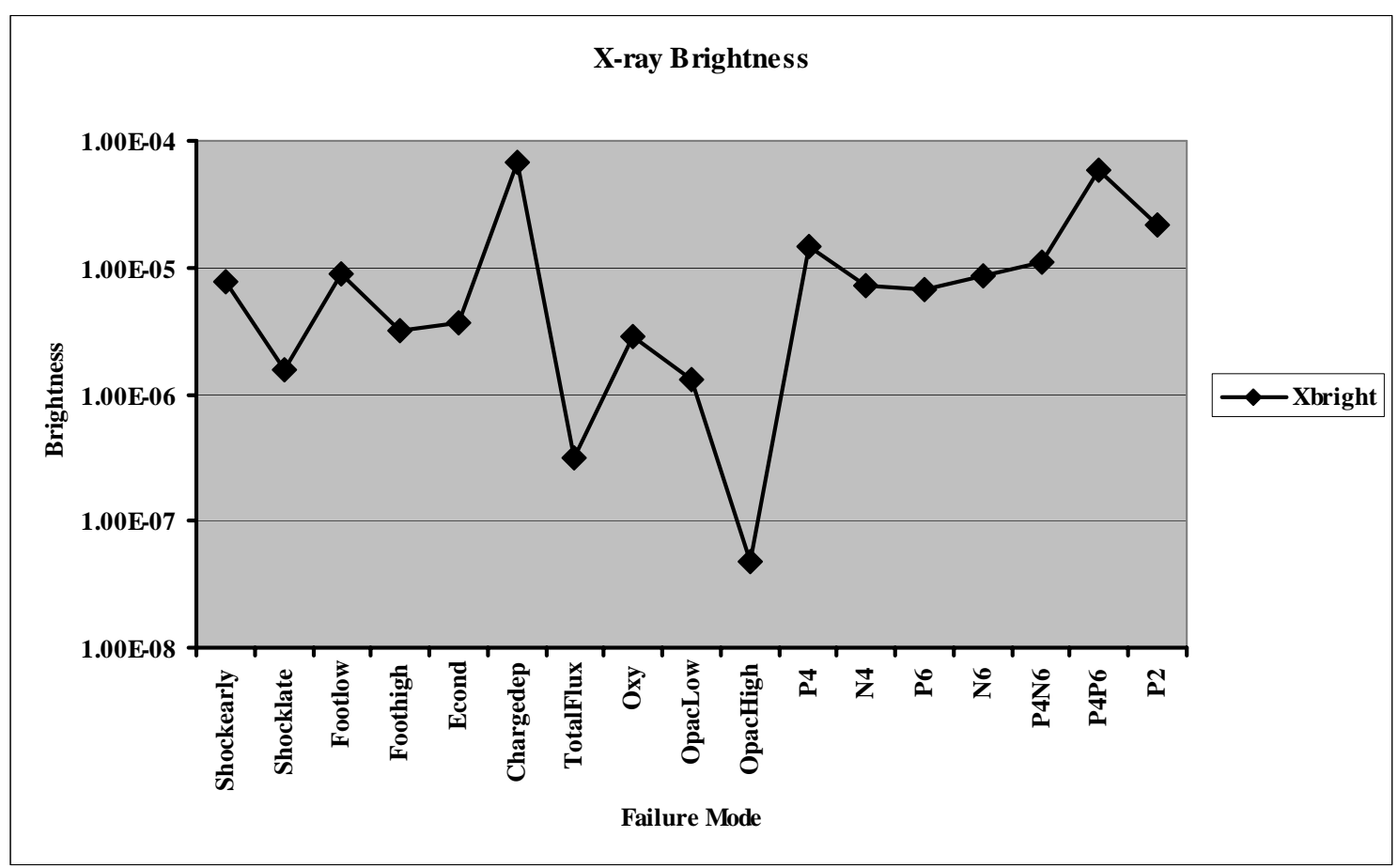

Figure 7. X-ray image brightness plotted as a function of failure mode.

\section{4) Neutron imaging resolution and contour levels of interest}

Core imaging is currently planned using both primary (12-17 MeV) and downscattered (6-10 MeV) neutrons. In order to quantify the required image resolution and the desired contour levels, we explored several two-dimensional drive asymmetry failure simulations in order to evaluate (1) How modal distortion information degrades as image blurring is added, (2) How modal distortions reflect the drive asymmetry imposed in the simulation. We focused specifically on pairs of simulations that have similar waist symmetry, and that therefore produce similar core distortions and images: P4/N6, and N4/P6.

We began by generating simulated one-quadrant images that were post-processed from the Lasnex hydrodynamics code and integrated over the appropriate neutron energy range (6-10 or 12-17 MeV). We then symmetrized these images to cover four quadrants, and introduced Gaussian blurring with a full-width at half-maximum of 0, 10 and $20 \mu \mathrm{m}$. We then generated contours of $15 \%$ and $80 \%$ constant fractional intensity relative to the peak image intensity, and generated Legendre mode plots from the following equation:

$$
A(\text { mode } \mathrm{l})=\frac{(2 l+1)}{4} \sum_{\theta_{j}=0}^{\theta_{j}=2 \pi}\left(R_{j}-R_{\text {avg }}\right) P_{l}\left(\cos \theta_{j}\right)\left|\sin \left(\theta_{j}\right)\right| \Delta \theta
$$

where $j$ refers to a point on the contour with radius $R_{j}$ and polar angle $\theta_{j}$ relative to the hohlraum axis, $\mathrm{R}_{\mathrm{avg}}$ is the average radius for all points relative to the center of mass, and $\mathrm{P}_{1}$ is the lth Legendre mode function. 
Downscattered and primary images and mode plots for the P6/N4 combination are shown in Figs. 8-13 below, for both 15\% and 80\% contour levels.

P6
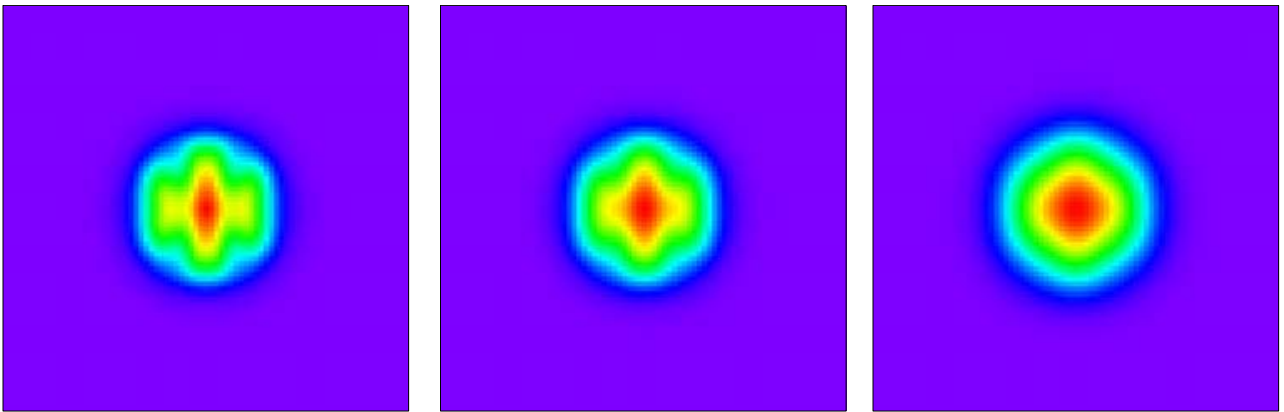

N4

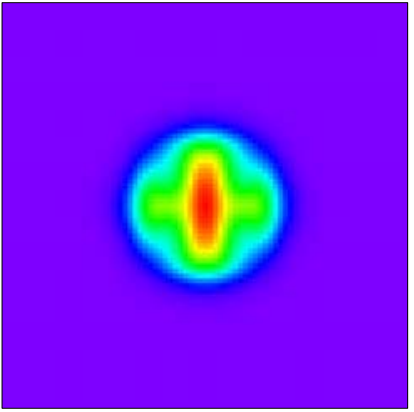

$0 \mu \mathrm{m}$

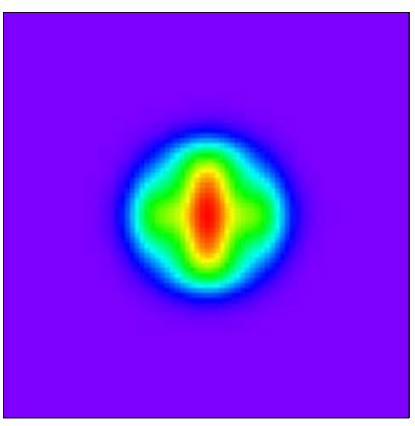

$10 \mu \mathrm{m}$

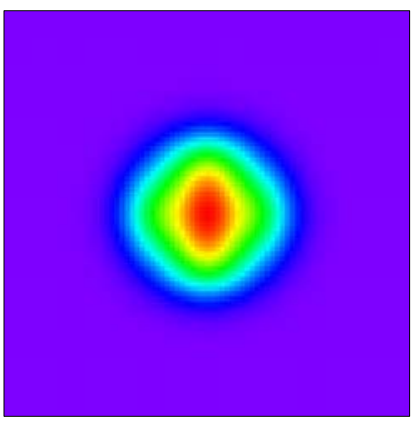

$20 \mu \mathrm{m}$

Figure 8: 6-10 MeV downscattered neutron images for the P6/N4 combination.
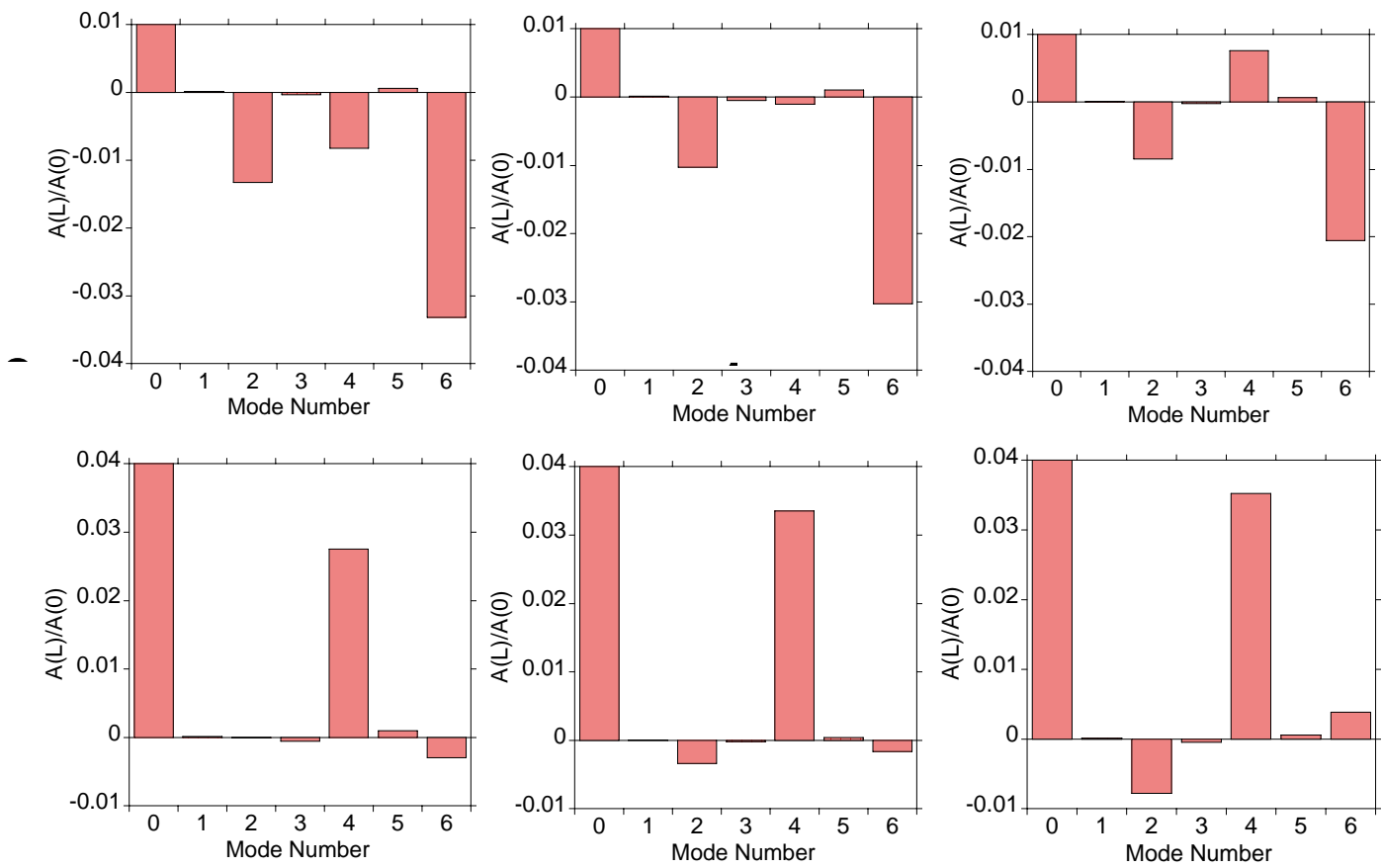

Figure 9: Mode plots at the 15\% contour for the images in Fig. 8. 

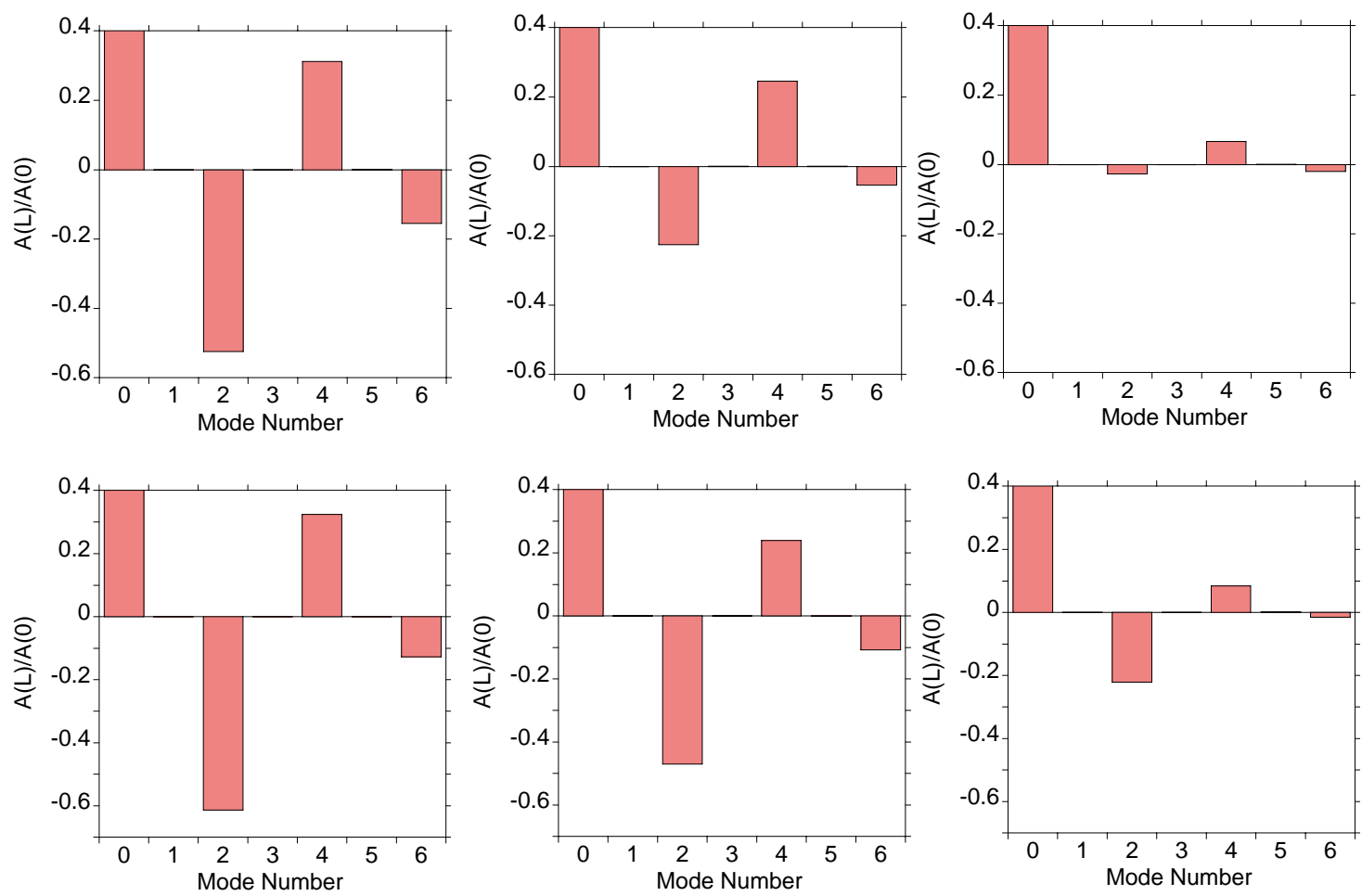

Figure 10: Mode plots at the $80 \%$ contour for the images in Fig. 8.

P6
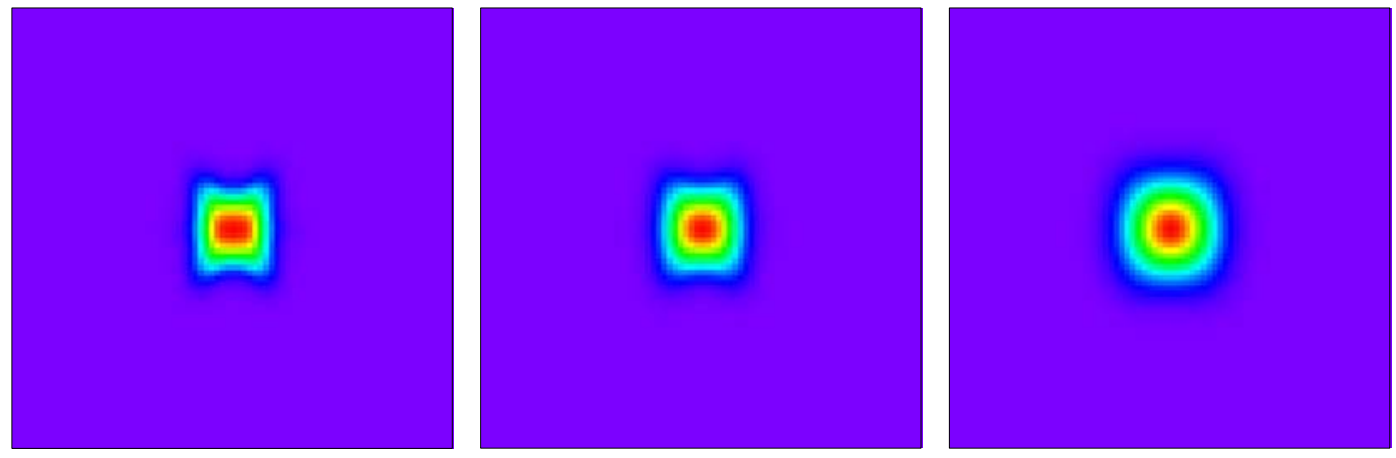

N4

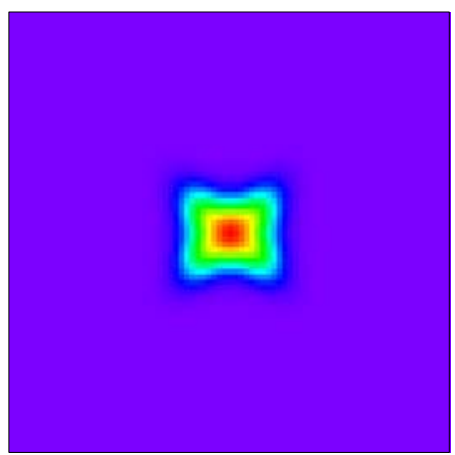

$0 \mu \mathrm{m}$

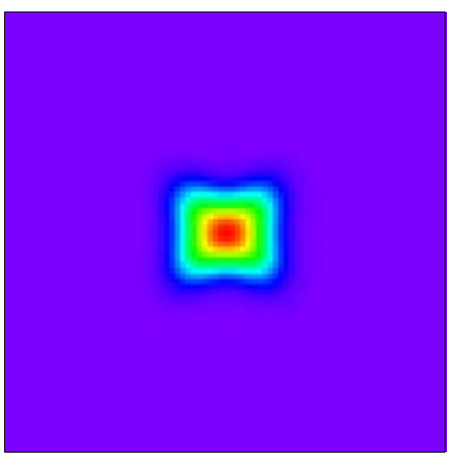

$10 \mu \mathrm{m}$

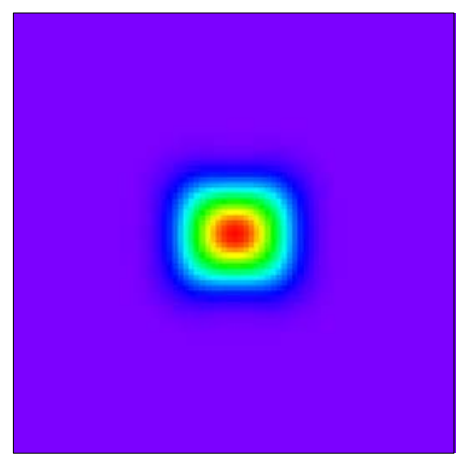

$20 \mu \mathrm{m}$

Figure 11: $12-17 \mathrm{MeV}$ primary neutron images for the P6/N4 combination. 

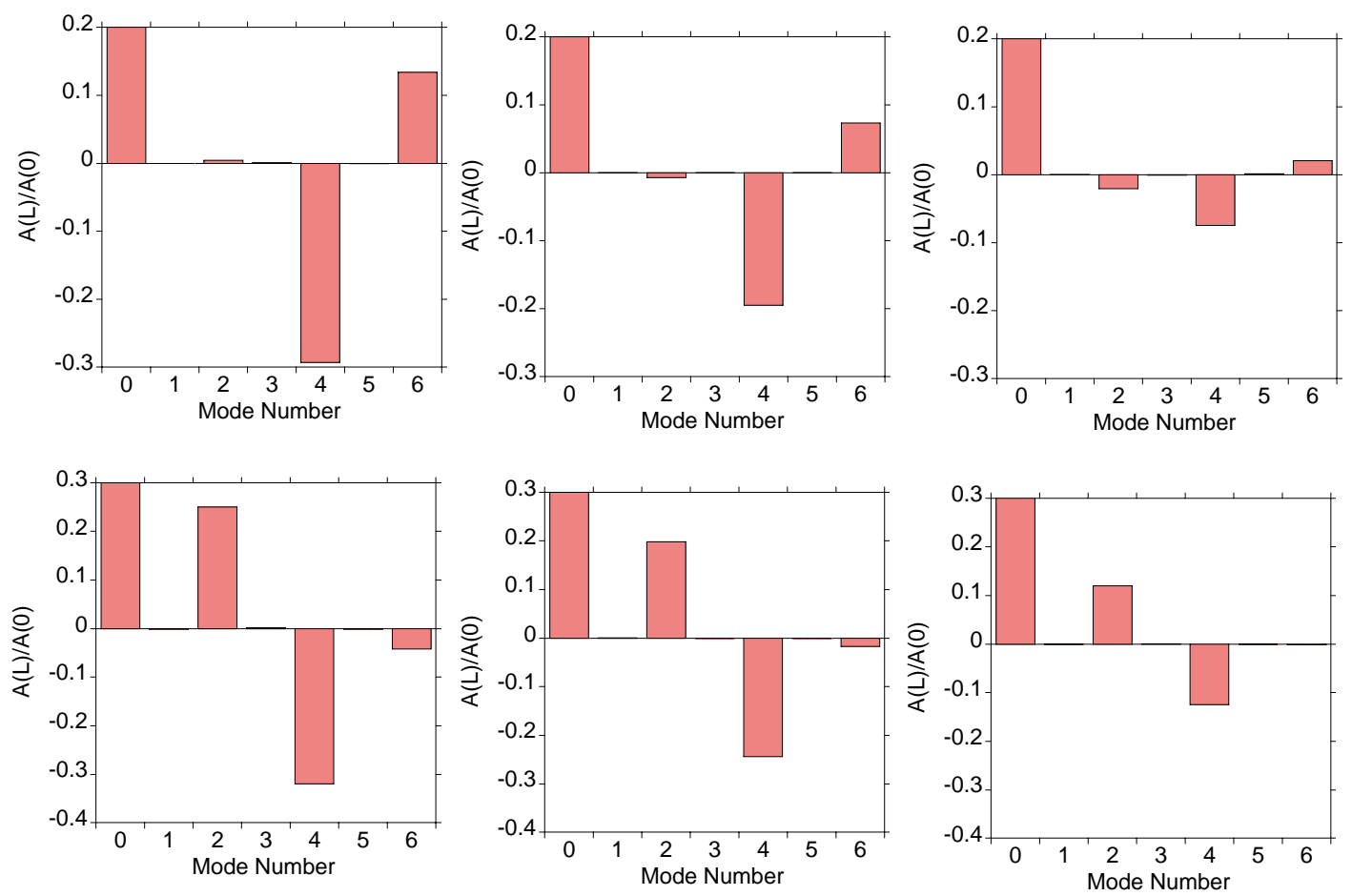

Figure 12: Mode plots at the 15\% contour for the images in Fig. 11.
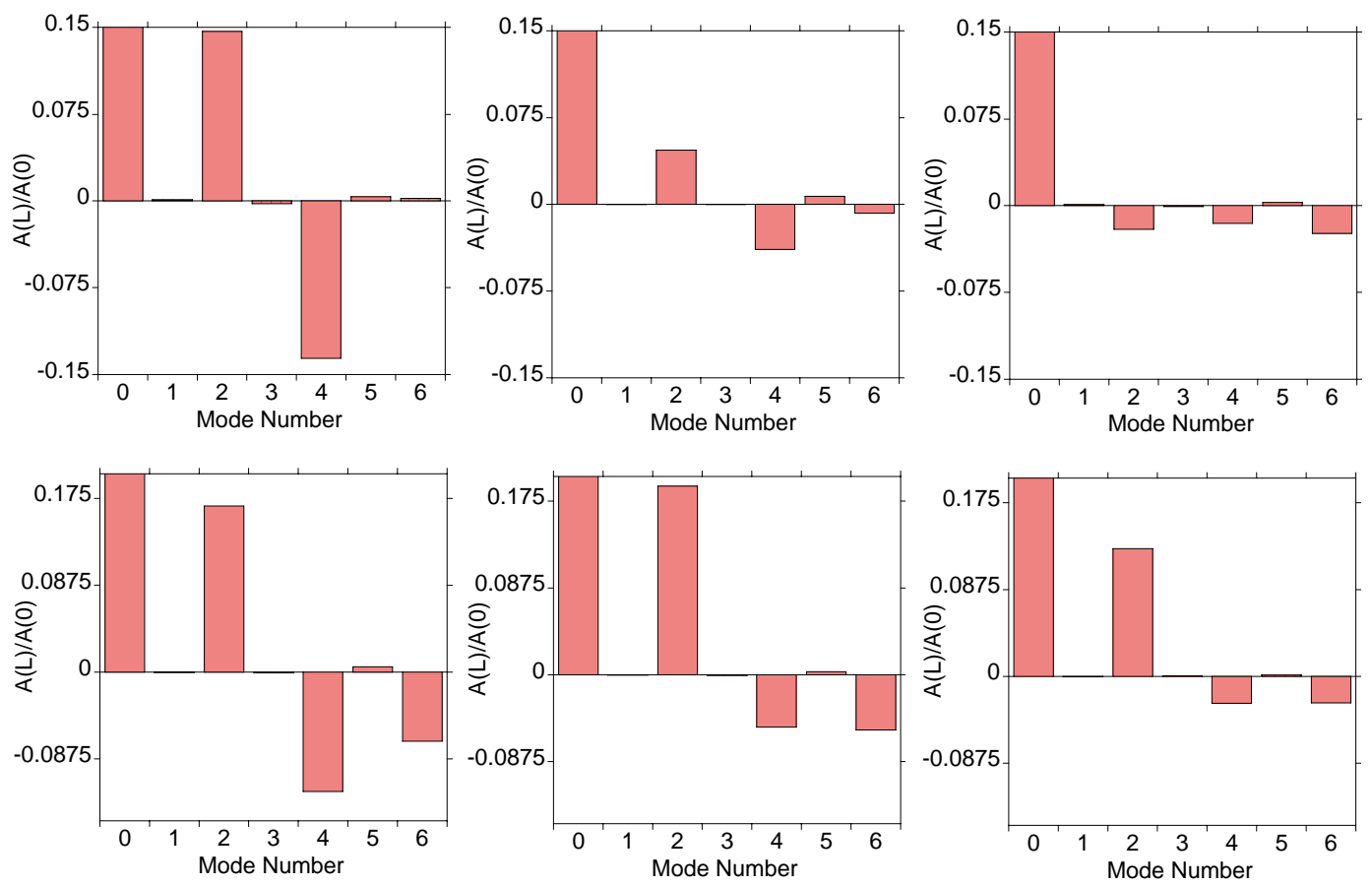

Figure 13: Mode plots at the 80\% contour for the images in Fig. 11. 
Downscattered and primary images and mode plots for the N6/P4 combination are shown in Figs. 14-19 below, for both 15\% and 80\% contour levels.

N6
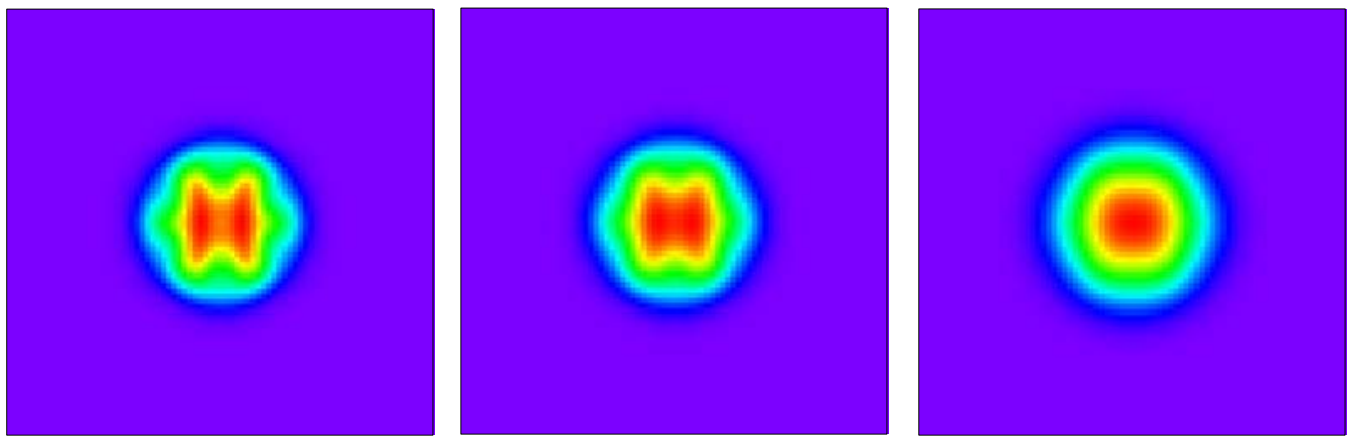

P4

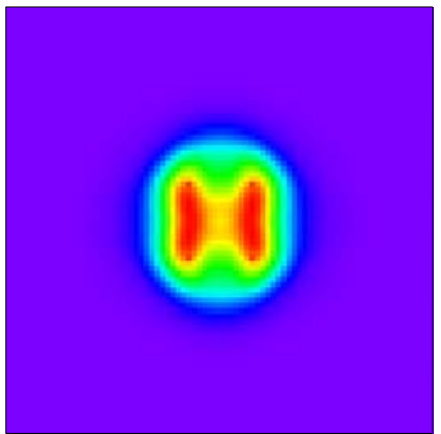

$0 \mu \mathrm{m}$

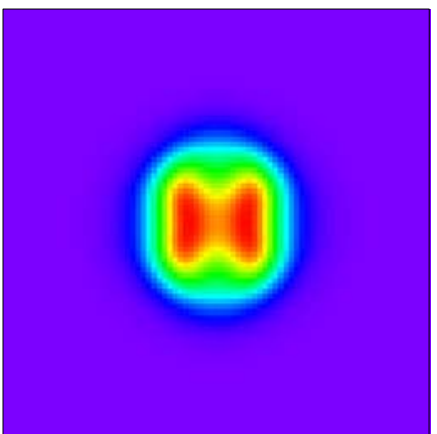

$10 \mu \mathrm{m}$

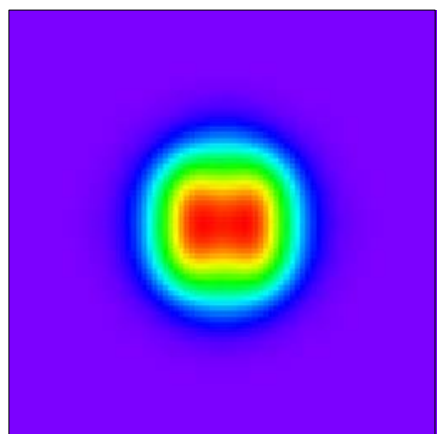

$20 \mu \mathrm{m}$

Figure 14: 6-10 MeV downscattered neutron images for the N6/P4 combination.
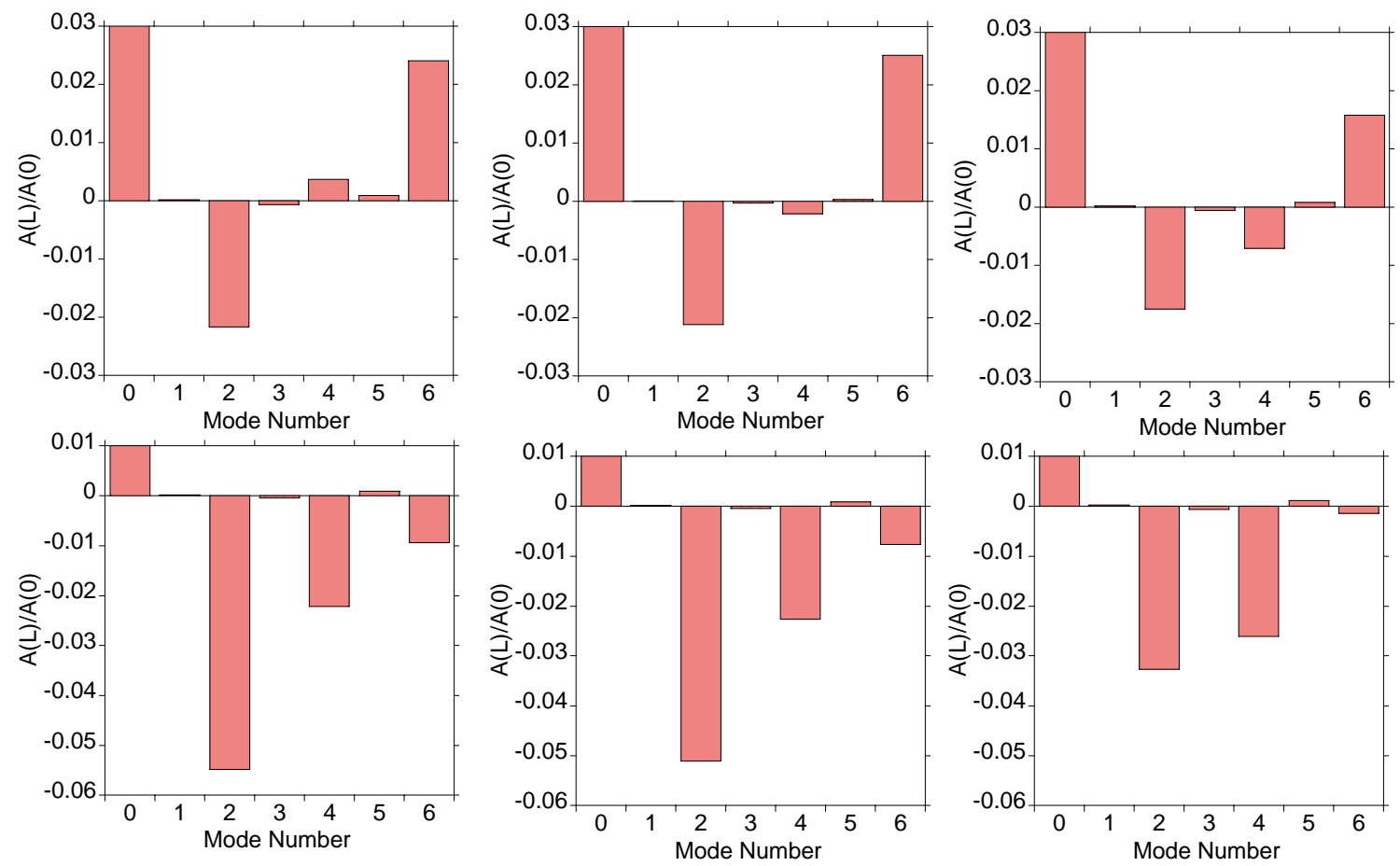

Figure 15: Mode plots at the 15\% contour for the images in Fig. 14. 

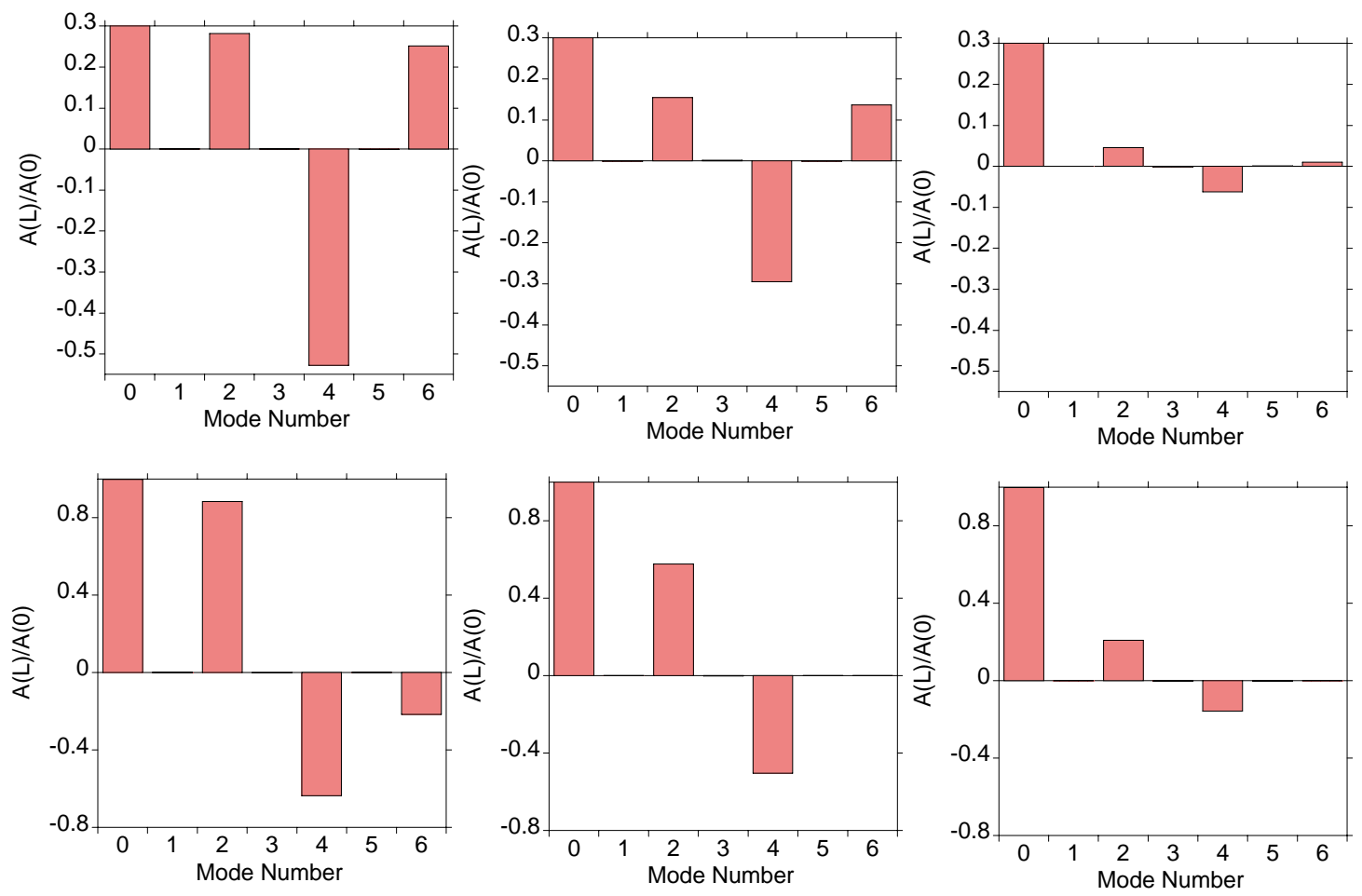

Figure 16: Mode plots at the 80\% contour for the images in Fig. 14.

N6
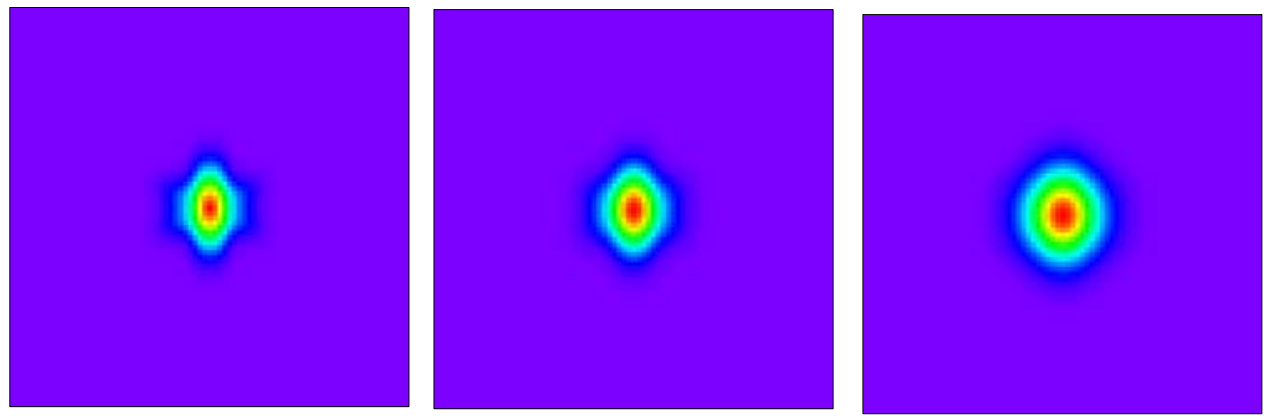

P4

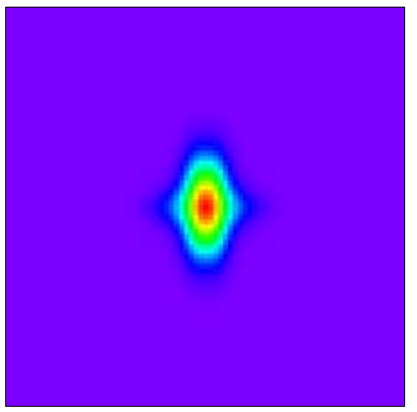

$0 \mu \mathrm{m}$

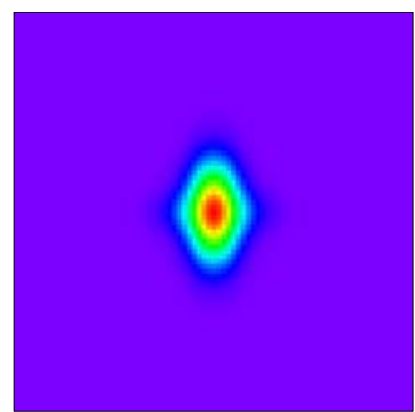

$10 \mu \mathrm{m}$

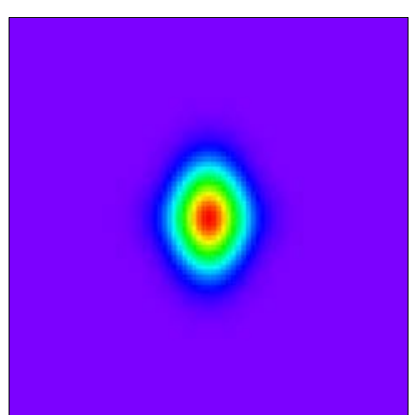

$20 \mu \mathrm{m}$

Figure 17: $12-17 \mathrm{MeV}$ primary neutron images for the N6/P4 combination. 

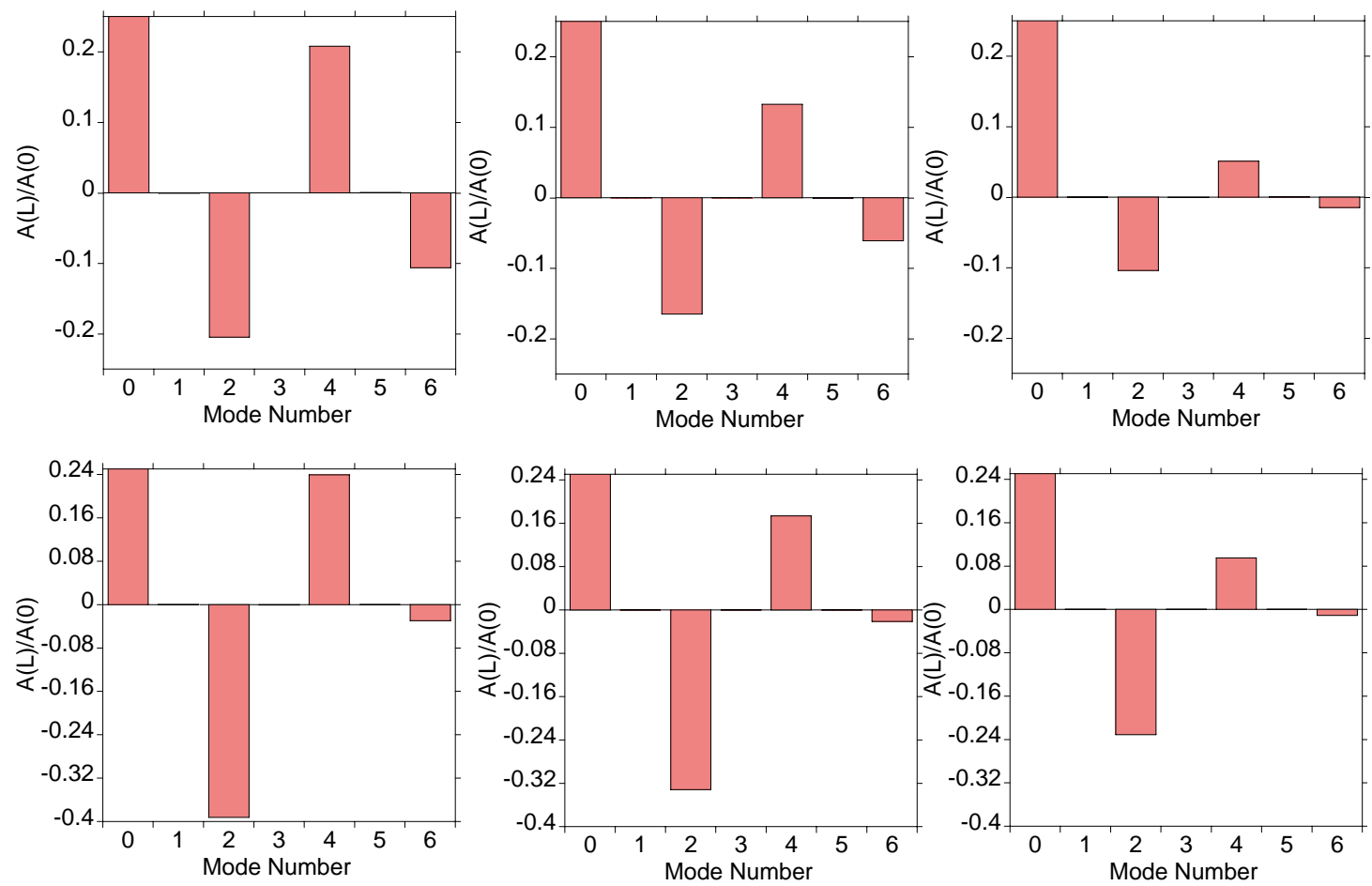

Figure 18: Mode plots at the 15\% contour for the images in Fig. 17.
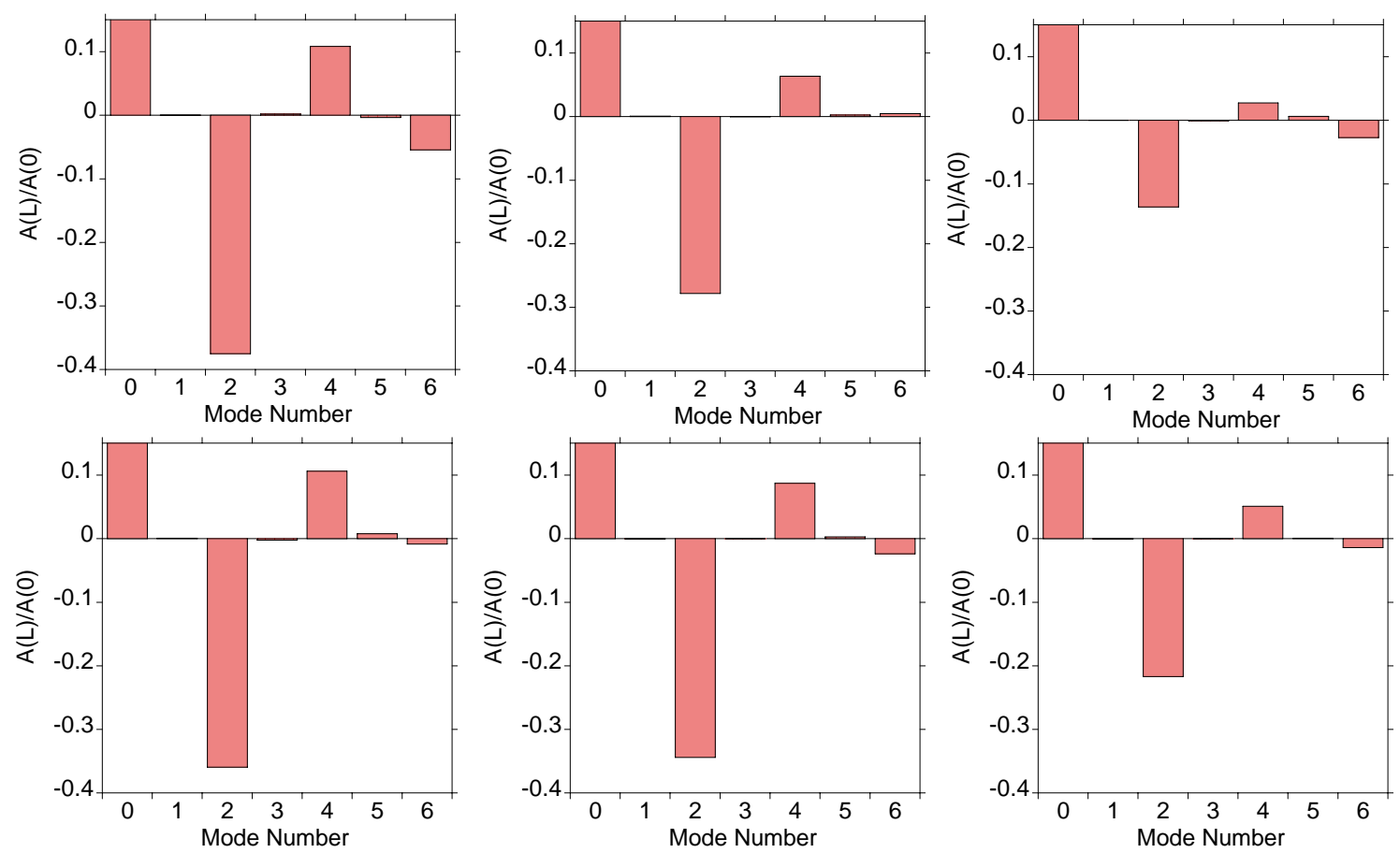

Figure 19: Mode plots at the 80\% contour for the images in Fig. 17. 
Several features are apparent from these results.

(1) In general, pure-mode drive asymmetries result in mixed-mode neutron images. There is no simple correlation between the symmetry of the images and the imposed drive symmetry, and images for a P6 failure are very similar to those predicted for an N4 failure. Likewise, N6 and P4 failures produce nearly identical images. This appears to be due to the similar waist drive symmetry between the pairs.

(2) The drive symmetry is best reproduced at low-level ( 15\%) contours, and least correlated at high-level $(\sim 80 \%)$ contours. While both regions are of interest, the lowlevel contours are probably more valuable for diagnosing failures.

(3) Blurring at the $10 \mu \mathrm{m}$ level is generally acceptable for both primary and downscattered images, but in many cases $20 \mu \mathrm{m}$ blurring either destroys the mode information present in the unblurred image or makes it more difficult to distinguish between P6/N4 and N6/P4 pairs. Blurring at the $20 \mu \mathrm{m}$ level may be acceptable for lowlevel contours in the downscattered neutron images.

\section{5) Emission x-ray imaging resolution and contour levels of interest}

Core x-ray imaging is currently planned for ignition experiments, with x-ray detection bandpass being determined by filtration and detector response curves. In order to quantify the required image resolution and the desired contour levels, we explored several two-dimensional drive asymmetry failure simulations in order to evaluate (1) How modal distortion information degrades as image blurring is added, (2) How modal distortions reflect the drive asymmetry imposed in the simulation. We followed the same procedures described above for neutron images, and generated the initial one-quadrant images in Lasnex using the expected filter transmission and detector response curves. Images and contour plots for the two P6/N4 and N6/P4 pairs are shown in Figs. 20-25 below. 

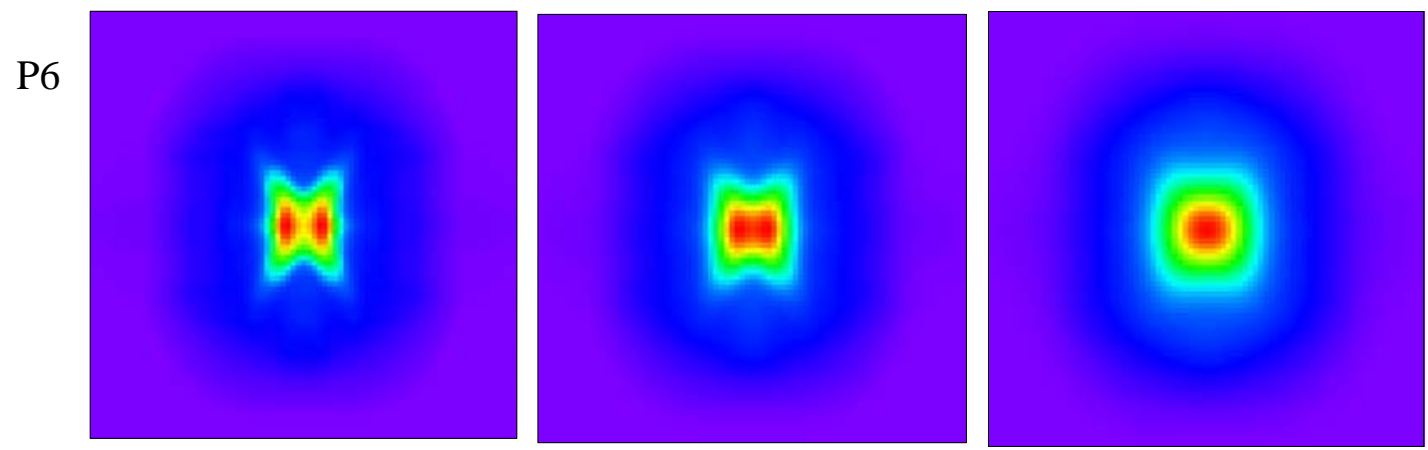

N4
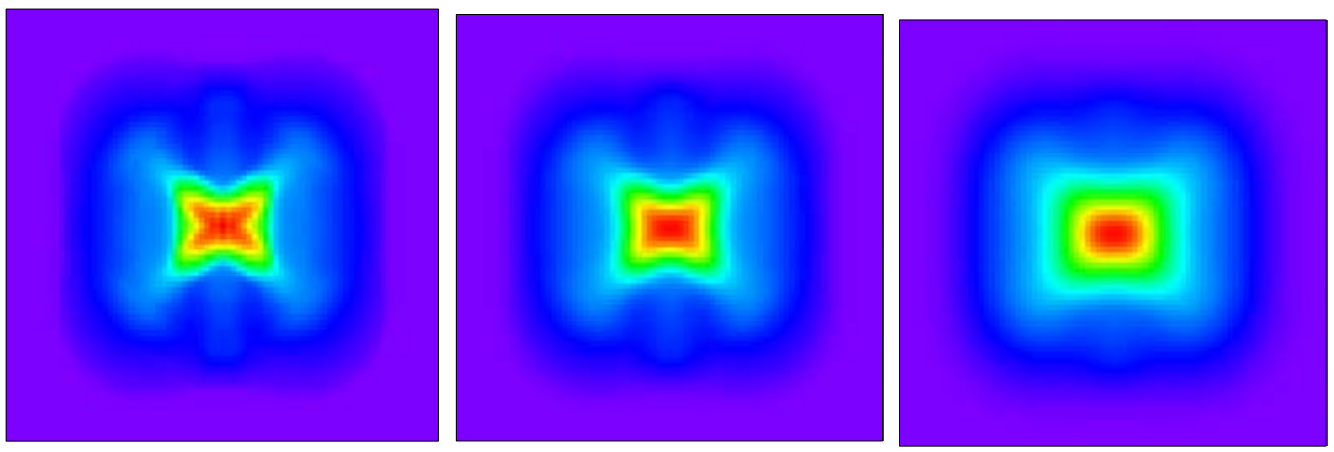

$0 \mu \mathrm{m}$

$10 \mu \mathrm{m}$

$20 \mu \mathrm{m}$

Figure 20: Filtered x-ray images for the P6/N4 combination.
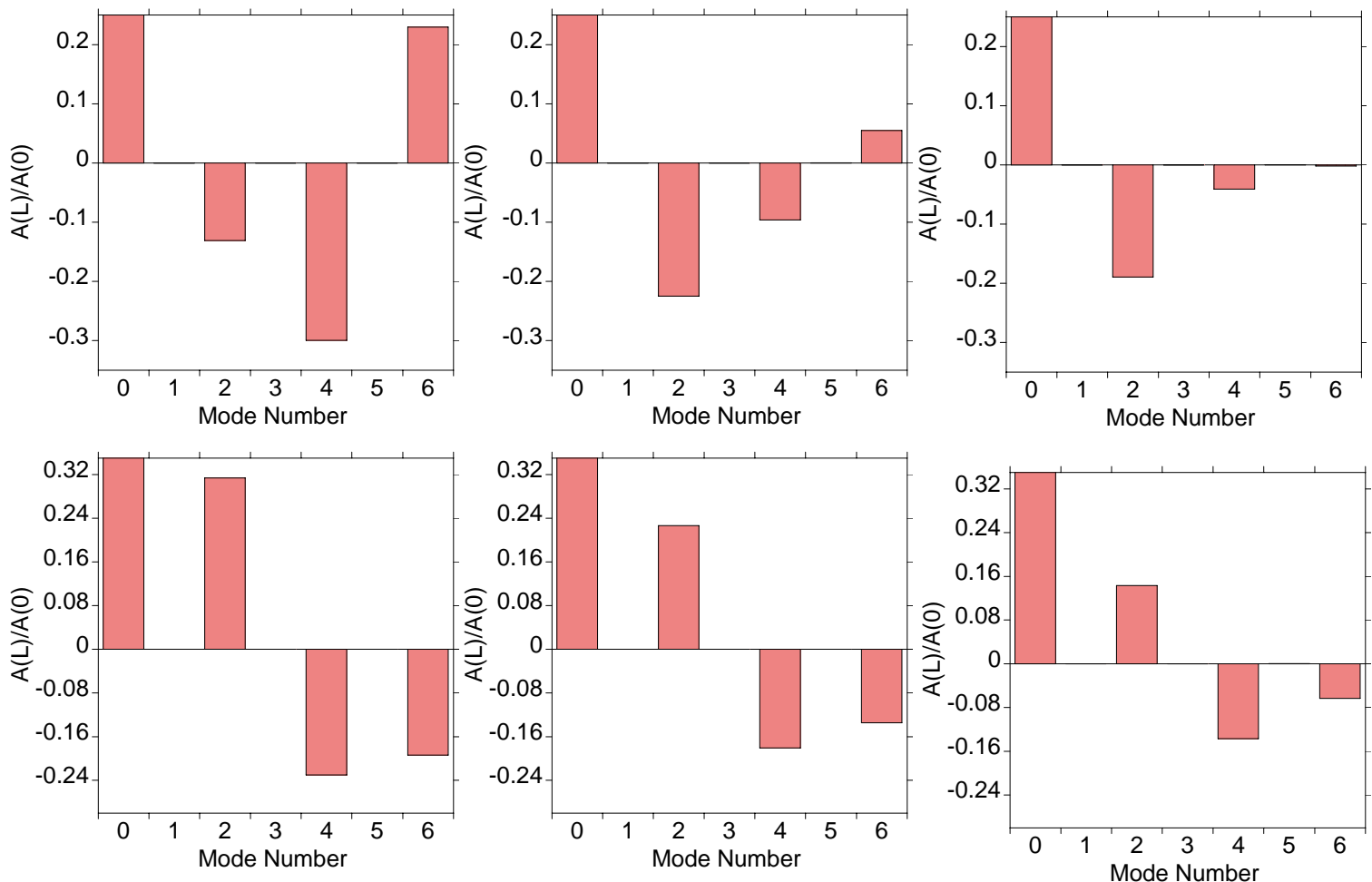

Figure 21: Mode plots at the 15\% contour for the images in Fig. 20. 

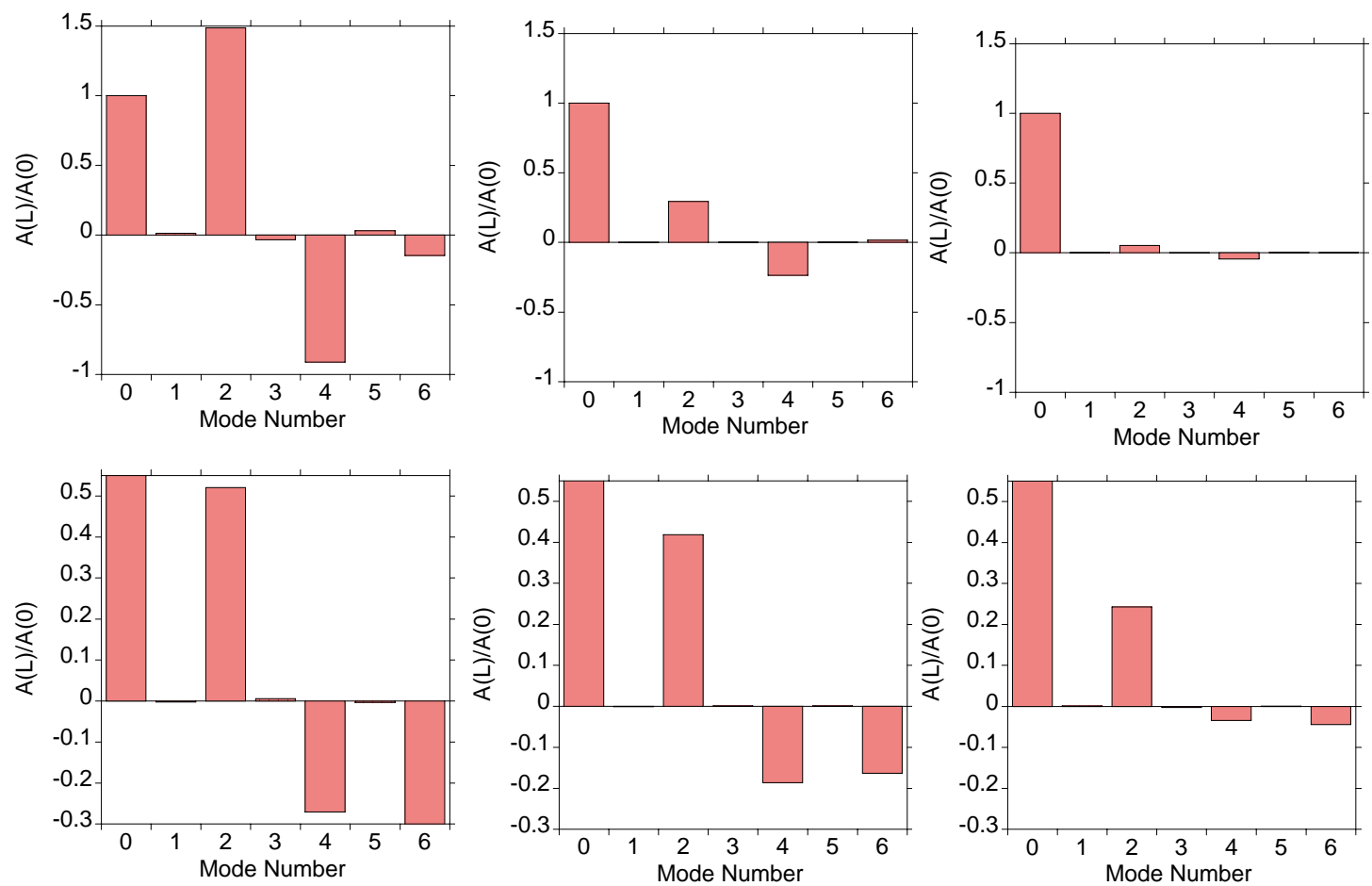

Figure 22: Mode plots at the $80 \%$ contour for the images in Fig. 20.

N6
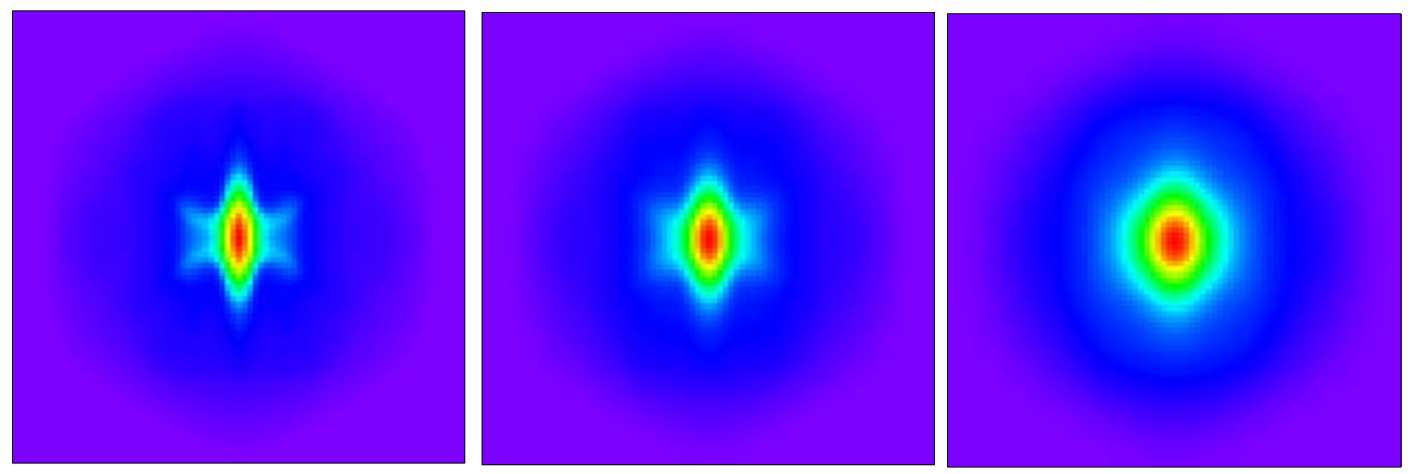

P4
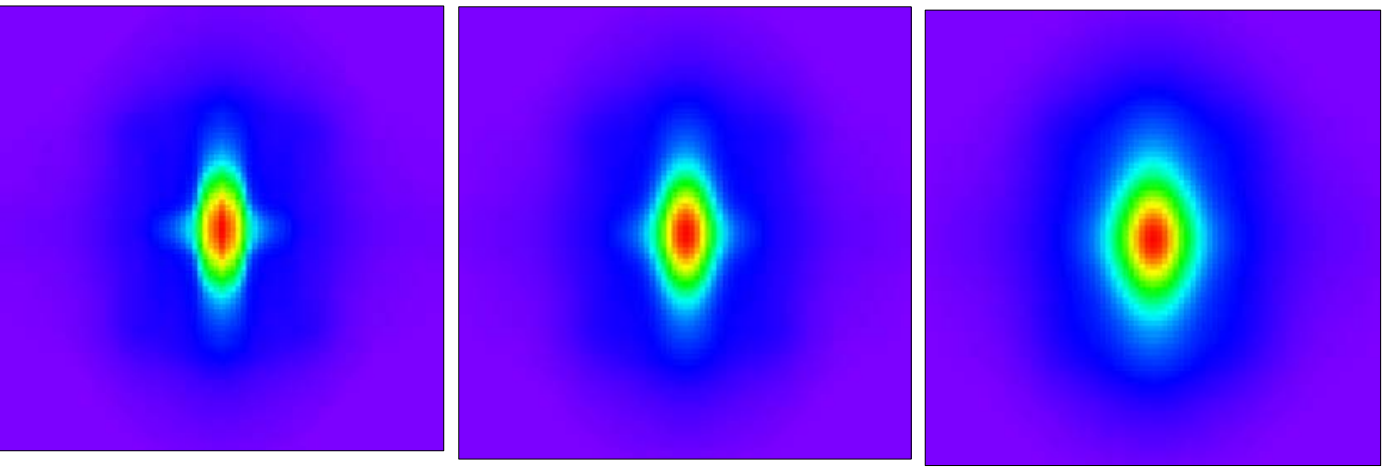

$0 \mu \mathrm{m}$

$10 \mu \mathrm{m}$

$20 \mu \mathrm{m}$

Figure 23: Filtered x-ray images for the N6/P4 combination. 

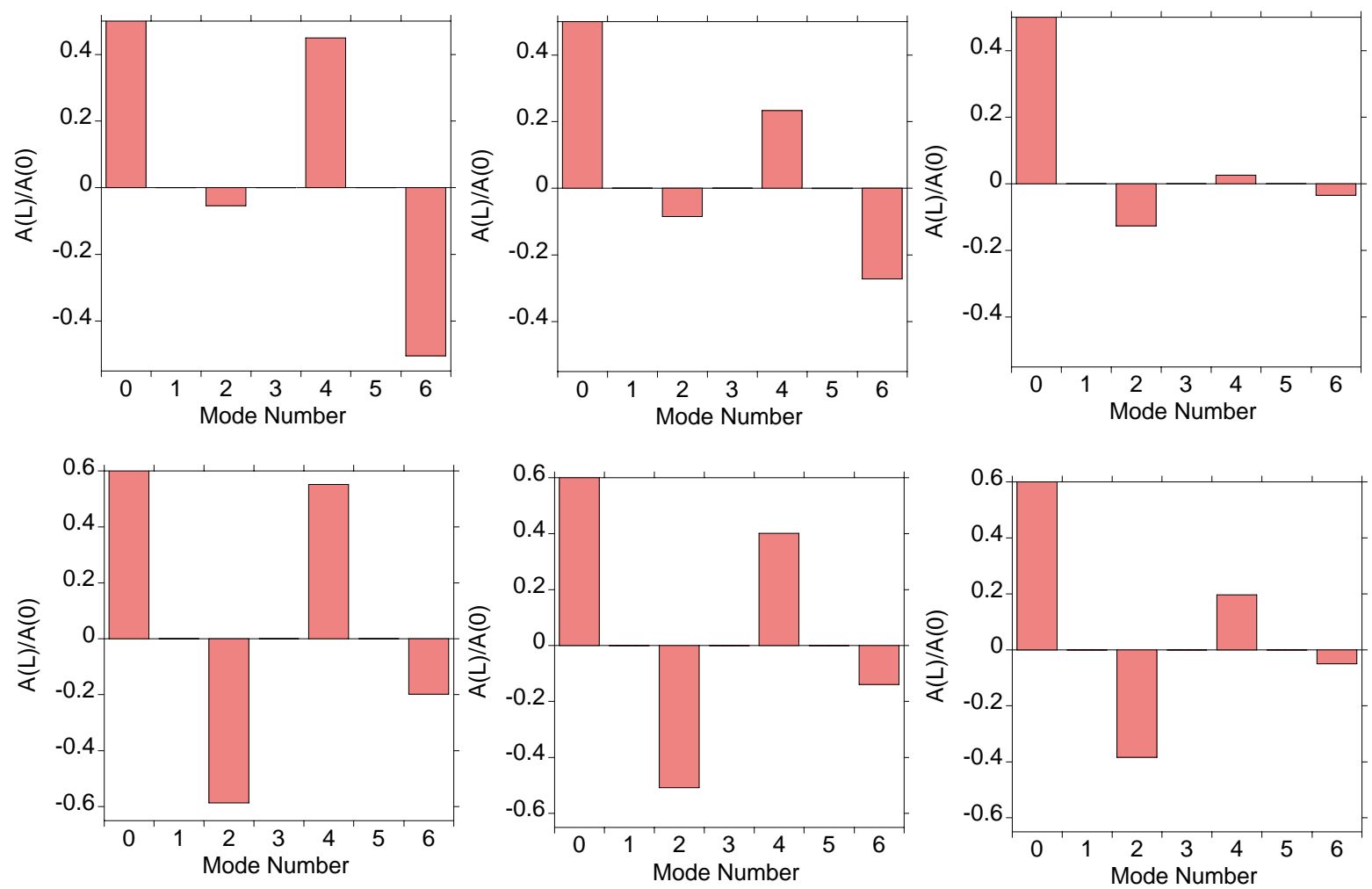

Figure 24: Mode plots at the 15\% contour for the images in Fig. 23.
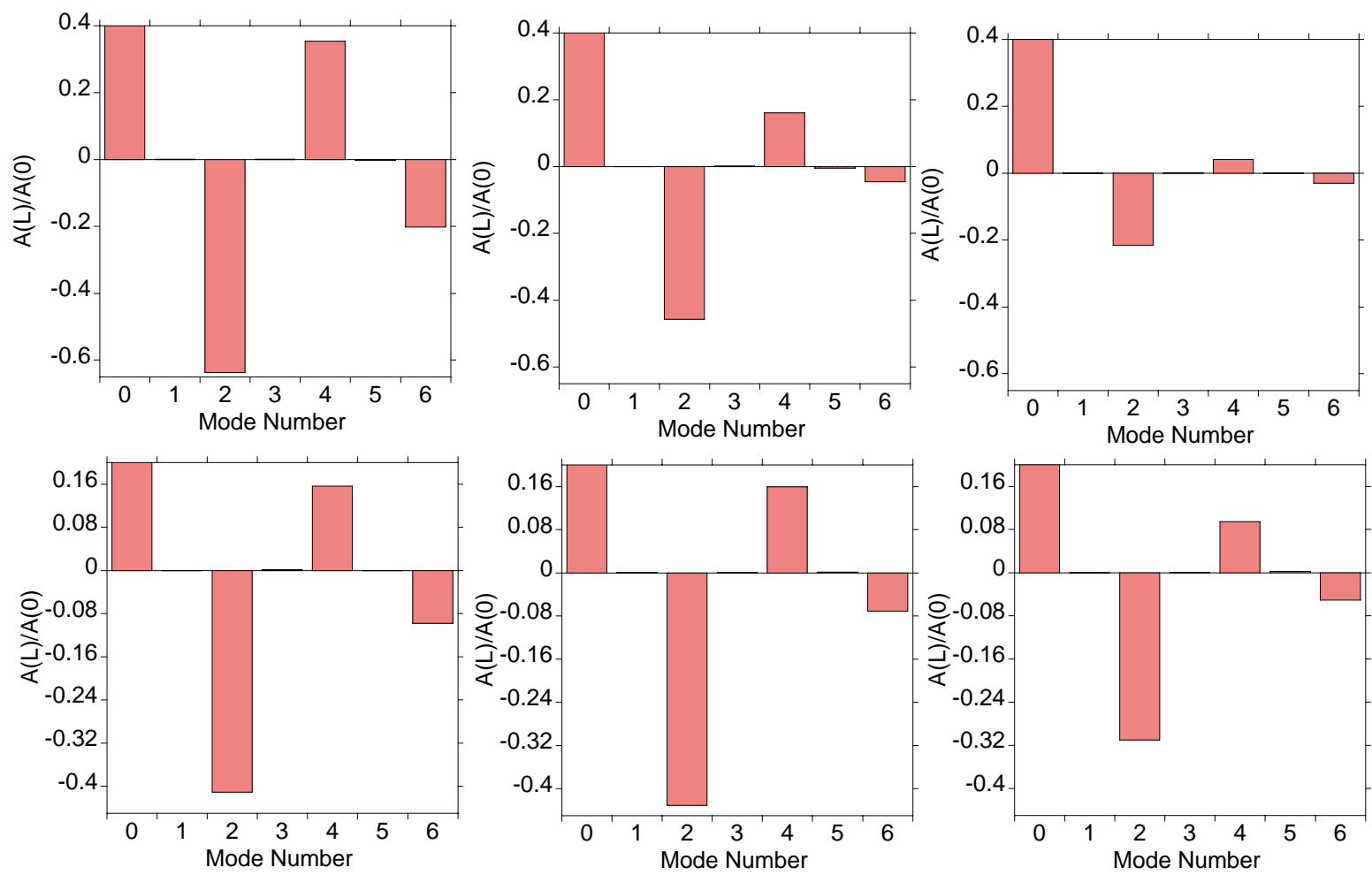

Figure 25: Mode plots at the 80\% contour for the images in Fig. 23. 
Several features are apparent from these results.

(1) Emission x-ray images are slightly larger than primary neutron images, but in general they provide the same information. Both are representations of the central hot core of the plasma, with primary neutrons being sensitive to regions of high ion temperature and $\mathrm{x}$ rays being (somewhat less) sensitive to regions of high electron temperature.

(2) The drive symmetry is best reproduced at low-level ( 15\%) contours, and least correlated at high-level $(\sim 80 \%)$ contours. While both regions are of interest, the lowlevel contours are probably more valuable for diagnosing failures.

(3) Blurring at the $10 \mu \mathrm{m}$ level is generally acceptable, but - as with primary neutron images - blurring at the $20 \mu \mathrm{m}$ level generally is not. 


\section{6) Summary}

The results of the above analysis are summarized in Table 1 below, along with proposed new requirements and diagnostic capabilities.

\begin{tabular}{|c|c|c|c|}
\hline & $\begin{array}{l}\text { Proposed New } \\
\text { Requirements }\end{array}$ & Old Requirements & Comments \\
\hline $\begin{array}{l}\text { Ion temperature } \\
\text { accuracy and precision }\end{array}$ & $1 \mathrm{keV}$ for MRS, NToF. & $\begin{array}{l}10 \% \text { Ti with NToF. } \\
\text { Better than } 3 \mathrm{MeV} \\
\text { energy resolution with } \\
\text { MRS. }\end{array}$ & $\begin{array}{l}\text { Not very sensitive to } \\
\text { failure mode. } \\
1 \mathrm{keV} \text { for hard failures } \\
\text { is equivilent to } 20 \% \text {. }\end{array}$ \\
\hline $\begin{array}{l}\text { Downscattered neutron } \\
\text { fraction accuracy and } \\
\text { precision }\end{array}$ & $\begin{array}{l}\text { 10\% with MRS and } \\
\text { NToF. }\end{array}$ & $\begin{array}{l}10 \% \text { absolute spectrum } \\
\text { with MRS. } \\
25 \% \text { for NToF. }\end{array}$ & $\begin{array}{l}30 \% \text { could still } \\
\text { distinguish some } \\
\text { failures }\end{array}$ \\
\hline $\begin{array}{l}\text { Tertiary neutron fraction } \\
\text { accuracy and precision }\end{array}$ & $\begin{array}{l}5 \% \text { goal for C } \\
\text { activation, MRS and } \\
\text { NToF, for primary } \\
\text { yields above 5e15 }\end{array}$ & $\begin{array}{l}\text { 50\% absolute with C } \\
\text { activation. } \\
\text { 10\% absolute with } \\
\text { MRS. } \\
\text { No requirements for } \\
\text { NToF. }\end{array}$ & $\begin{array}{l}50 \% \text { could still } \\
\text { distinguish some } \\
\text { failures }\end{array}$ \\
\hline $\begin{array}{l}\text { Gamma bang time } \\
\text { accuracy and precision }\end{array}$ & 50 ps for GBT. & 40 ps for GBT. & \\
\hline $\begin{array}{l}\text { X-ray bang time } \\
\text { accuracy and precision }\end{array}$ & None. & None. & $\begin{array}{l}\text { X-ray bangtime } \\
\text { probably redundant with } \\
\text { gamma bang time, but } \\
\text { would have same } 50 \text { ps } \\
\text { requirement. }\end{array}$ \\
\hline $\begin{array}{l}\text { Gamma burn width } \\
\text { accuracy and precision }\end{array}$ & 10 ps for GBT. & None for GBT. & $\begin{array}{l}\text { New requirement on } \\
\text { GBT, essentially } \\
\text { mandates a streak } \\
\text { camera detector. }\end{array}$ \\
\hline $\begin{array}{l}\text { X-ray burn width } \\
\text { accuracy and precision }\end{array}$ & 10 ps. & None. & $\begin{array}{l}\text { New diagnostic, value in } \\
\text { measuring along with } \\
\text { gamma burn width }\end{array}$ \\
\hline $\begin{array}{l}\text { Filtered time-integrated } \\
\text { x-ray emission } \\
\text { brightness, absolute }\end{array}$ & $\begin{array}{l}\text { Factor of } 2 \text { absolute } \mathrm{x}- \\
\text { ray flux measurement } \\
\text { capability with HEXRI. }\end{array}$ & None. & $\begin{array}{l}\text { New, value in } \\
\text { measuring. }\end{array}$ \\
\hline $\begin{array}{l}\text { Primary neutron } \\
\text { resolution }\end{array}$ & $\begin{array}{l}10 \mu \mathrm{m} \text { Gaussian for } \\
\text { NIS. }\end{array}$ & $\begin{array}{l}10 \mu \mathrm{m} \text { Gaussian for } \\
\text { NIS. }\end{array}$ & \\
\hline $\begin{array}{l}\text { Primary neutron contour } \\
\text { level of interest }\end{array}$ & $\begin{array}{l}\text { S/N greater than } 10 \text { at } \\
15 \% \text { contour for NIS. }\end{array}$ & $\begin{array}{l}\text { S/N greater than } 10 \text { at } \\
20 \% \text { contour for NIS. }\end{array}$ & $\begin{array}{l}\text { Some value in reducing } \\
\text { contour level to } 15 \% \text {. }\end{array}$ \\
\hline $\begin{array}{l}\text { Downscattered neutron } \\
\text { resolution }\end{array}$ & $\begin{array}{l}10 \mu \mathrm{m} \text { Gaussian at high } \\
\text { contours, } 20 \mu \mathrm{m} \\
\text { Gaussian at } 15 \% \\
\text { contour, for NIS. }\end{array}$ & $\begin{array}{l}10 \mu \mathrm{m} \text { Gaussian for } \\
\text { NIS. }\end{array}$ & $\begin{array}{l}\text { Can relax to } 20 \mu \mathrm{m} \text { at } \\
15 \% \text { contour level. }\end{array}$ \\
\hline $\begin{array}{l}\text { Downscattered neutron } \\
\text { contour level of interest }\end{array}$ & $\begin{array}{l}\text { S/N greater than } 10 \text { at } \\
15 \% \text { contour for NIS. }\end{array}$ & $\begin{array}{l}\text { S/N greater than } 10 \text { at } \\
20 \% \text { contour for NIS. }\end{array}$ & $\begin{array}{l}\text { Some value in reducing } \\
\text { contour level to } 15 \% \text {. }\end{array}$ \\
\hline $\begin{array}{l}\text { X-ray emission image } \\
\text { resolution }\end{array}$ & $\begin{array}{l}10 \mu \mathrm{m} \text { for standard } \\
\text { detected bandpass of } \\
\text { HEXRI. }\end{array}$ & $\begin{array}{l}10 \mu \mathrm{m} \text { at } 9 \mathrm{keV}, 20 \mu \mathrm{m} \\
\text { at other energies for } \\
\text { HEXRI. }\end{array}$ & \\
\hline
\end{tabular}

